\title{
Hybrid glacier Inventory, Gravimetry and Altimetry (HIGA) mass balance product for Greenland and the Canadian Arctic
}

\author{
William Colgan ${ }^{1,2}$, Waleed Abdalati ${ }^{2}$, Michele Citterio ${ }^{1}$, Beata Csatho ${ }^{3}$, Xavier Fettweis ${ }^{4}$, \\ Scott Luthcke ${ }^{5}$, Geir Moholdt ${ }^{6,7}$, Sebastian B. Simonsen ${ }^{8}$ and Manfred Stober ${ }^{9}$ \\ ${ }^{1}$ Marine Geology and Glaciology, Geological Survey of Denmark and Greenland, Copenhagen, Denmark \\ ${ }^{2}$ Cooperative Institute for Research in Environmental Sciences, University of Colorado, Boulder, CO, USA \\ ${ }^{3}$ Department of Geology, State University of New York, Buffalo, NY, USA \\ ${ }^{4}$ Department of Geography, University of Liége, Liége, Belgium \\ ${ }^{5}$ Goddard Space Flight Center, National Aeronautics and Space Administration, Greenbelt, MD, USA \\ ${ }^{6}$ Scripps Institution of Oceanography, University of California, San Diego, CA, USA \\ ${ }^{7}$ Norwegian Polar Institute, Fram Center, Troms $\varnothing$, Norway \\ ${ }^{8}$ Technical University of Denmark, Lyngby, Denmark \\ ${ }^{9}$ Stuttgart University of Applied Sciences, Stuttgart, Germany
}

\section{ABSTRACT}

We present a novel inversion algorithm that generates a mass balance field that is simultaneously consistent with independent observations of glacier inventory derived from optical imagery, cryosphere-attributed mass trends derived from satellite gravimetry, and ice surface elevation trends derived from airborne and satellite altimetry. We use this algorithm to assess mass balance across Greenland and the Canadian Arctic over the Sep-2003 to Oct-2009 period at $26 \mathrm{~km}$ resolution. We evaluate local algorithm-inferred mass balance against forty in situ point observations. This evaluation yields an RMSE of $0.15 \mathrm{mWE} / \mathrm{a}$, and highlights a paucity of in situ observations from regions of high dynamic mass loss and peripheral glaciers. We assess mass losses of $212 \pm 67 \mathrm{Gt} / \mathrm{a}$ to the Greenland ice sheet proper, $38 \pm 11 \mathrm{Gt} / \mathrm{a}$ to peripheral glaciers in Greenland, and $42 \pm 11 \mathrm{Gt} / \mathrm{a}$ to glaciers in the Canadian Arctic. These magnitudes of mass loss are dependent on the gravimetry-derived spherical harmonic mass trend we invert. We spatially partition the transient glacier continuity equation by differencing algorithm-inferred mass balance from modelled surface mass balance, in order to solve the horizontal divergence of ice flux as a residual. This residual ice dynamic field infers flux divergence (or submergent flow) in the ice sheet accumulation area and at tidewater margins, and flux convergence (or emergent flow) in land-terminating ablation areas, which is consistent with continuum mechanics theory.

\section{INTRODUCTION}


Greenland is presently the single largest cryospheric source of sea level rise, contributing $0.73 \pm 0.08 \mathrm{~mm} / \mathrm{a}$ of sea level rise during the 2005 to 2010 period (Shepherd et al., 2012). Greenland's contribution to sea level rise was approximately equally divided between anomalies in meltwater runoff and iceberg calving during the 2000 to 2008 period (van den Broeke et al., 2009). Since 2009, however, meltwater runoff has been responsible for the majority of Greenland mass loss (Enderlin et al., 2014). Pursuing a process-level understanding of the contemporary partition of mass loss requires characterizing the spatial pattern of mass balance at a sub-basin or glacier scale, which allows mass balance to be differenced from modelled surface mass balance in order to solve for the ice dynamic component of mass change through iceberg calving. Accurate knowledge of the contemporary partitioning of mass loss between meltwater runoff and iceberg calving can serve as a key diagnostic modelling target, in order to improve confidence in prognostic model simulations.

Three methods are available for assessing mass balance at the ice sheet scale: (i) inputoutput, (ii) altimetry, and (iii) gravimetry. The first approach, also known as the mass budget approach, differences ice discharge estimated near the grounding line of outlet glaciers from surface mass balance modelled over the ice sheet (e.g. Rignot et al., 2008; van den Broeke et al., 2009). The second approach converts ice surface elevation trends observed by repeat airborne or modelling (e.g. Sørensen et al. 2011; Zwally et al., 2011). The third approach uses repeat satellite gravimetry observations and numerous geophysical forward models to assess cryospheric mass trends (e.g. Velicogna and Wahr, 2005; Wu et al., 2010). Each method has unique advantages and disadvantages relative to the other methods (Alley et al., 2007). While satellite altimetry characterizes the spatial variability of surface elevation trends at relatively high resolution, it relies on forward modelling of complex firn processes to estimate mass trends. Conversely, the cryospheric mass trends observed by satellite gravimetry and isolated by forward models, while absolute measurements of cryosphere-attributed mass trends to moderate spatial resolution. In this process, we overcome two complementary weaknesses: dependence on modelling complex

66 firn processes as well as the fundamental spatial resolution of satellite gravimetry. The $26 \mathrm{~km}$ 
simultaneously consistent with: (i) ice-sheet and glacier inventory derived from optical imagery, (ii) gravimetry-derived cryospheric mass trends, and (iii) altimetry-derived ice surface elevation trends. We refer to this as a Hybrid glacier Inventory, Gravimetry and Altimetry (HIGA) product. This data product is available in the supplementary material associated with this paper.

\section{DATA}

Our inversion algorithm requires three distinct pieces of input data: (i) fractional ice coverage derived from optical imagery, (ii) cryosphere-attributed mass trends derived from satellite gravimetry, and (iii) ice surface elevation trends derived from satellite and airborne altimetry. We compile each of these datasets over a common region of interest focused on Greenland and the Canadian Arctic (Figure 1). Our time interval of interest is the Sep-2003 to Oct-2009 Ice, Cloud and land Elevation Satellite (ICESat) operational period. We assess mass balance in ten geographic sectors, eight in Greenland and two in the Canadian Arctic (Figure 2). The eight Greenland sectors are equivalent to the eight major ice sheet drainage systems delineated by Zwally et al. (2012), but have been extended beyond the ice sheet margin to also encompass peripheral glaciers and ice caps. The two Canadian Arctic sectors are equivalent to those employed by Gardner et al. (2011). Shapefiles of these ten sector boundaries are available in the supplementary online material associated with this paper.

\subsection{Glacier inventory}

We calculate fractional ice coverage within our study region by clipping glacier inventory polygons with a polygon fishnet matching the inversion grid. We then sum the glacierized area within each grid cell, and scale areas to correct for projection-related distortion. In Greenland, we sum peripheral glacier and ice sheet coverage separately. The Greenland glacier inventory data are derived from aerophotogrammetry with a polygon accuracy of $10 \mathrm{~m}$ (Citterio and Ahlstrøm, 2013). This inventory has previously classified glaciers and ice caps demonstrating "no" (class zero or CL0) or "weak" (class one or CL1) connectivity with the ice sheet proper as Greenland peripheral glaciers, and glaciers demonstrating "strong" (class two or CL2) connectivity with the ice sheet as part of the Greenland ice sheet proper. The Citterio and Ahlstrøm (2013) glacier inventory we employ contains a peripheral glacier area of 88,083 \pm $1,240 \mathrm{~km}^{2}$, which is most analogous to the $89,273 \pm 2,767 \mathrm{~km}^{2}$ of "CL0+1" peripheral glacier 
area contained in the Rastner et al. (2013) glacier inventory. Importantly, both the Citterio and Ahlstrøm (2013) and Rastner et al. (2013) "CL0+1" inventories classify the Geikie Plateau in East Greenland and the Julianehåb Ice Cap in South Greenland as ice sheet proper. The Canadian glacier inventory data are derived from the Randolph Glacier Inventory (RGI) version 3.0 (Pfeffer et al., 2014). The main advance of RGI 3.0 over RGI 2.0 was the identification of tidewater glaciers, and separation of glacier complexes into individual glaciers in nearly all regions of the world, while the main advance of RGI 4.0 over the RGI 3.0 version we employ was the addition of topographic and hypsometric attributes for nearly all glaciers (Arendt et al., 2014). We employ both the North and South Canadian Arctic (RGI regions 3 and 4), which are primarily based on Landsat imagery with polygon accuracy of about $30 \mathrm{~m}$. We also use the RGI to calculate fractional ice coverage over Svalbard and Iceland (RGI regions 6 and 7) in the farfield of our inversion domain. We assume the glacier polygons in both the Citterio and Ahlstrøm (2013) and Pfeffer et al. (2014) inventories are representative of ice coverage during the Sep2003 to Oct-2009 study period.

\subsection{Gravimetry-derived cryospheric mass trends}

The satellite gravimetry-derived mass trends and associated $1 \sigma$ uncertainty that we employ are based on Gravity Recovery and Climate Experiment (GRACE) observations collected during the Sep-2003 to Oct-2009 period we adopt. As described below, these mass trends are spherical harmonic expressions of local mass concentration solutions. The study period we adopt, which corresponds to the ICESat operational period, is 21 months shorter than the GRACE comparison period adopted by the Ice sheet Mass Balance Inter-comparison Exercise (IMBIE; Dec-2003 to Dec-2010; Shepherd et al., 2012). Given that the spatial distribution of mass trends in Greenland is non-stationary, with mass loss accelerating in Northwest Greenland and decelerating in Southeast Greenland after 2009 (Khan et al., 2010), we employ gravimetry-derived mass trends over the ICESat operational period, rather than adopt the IMBIE GRACE period. As a result of ensuring identical ICESat and GRACE observation periods, the mass trends we present here, although ultimately constrained by satellite gravimetry, are not directly comparable to GRACE-derived mass trends assessed by the IMBIE.

The gravimetry-derived cryospheric mass trend product we employ is analogous to that described in Colgan et al. (2013). This mascon solution is estimated directly from the formal 
reduction of GRACE K-Band inter-satellite Range Rate (KBRR) data, processing the level 1B (L1B) data, including attitude and accelerometer data, and has a spatial resolution of $\sim 110 \mathrm{~km}$. Forward models for ocean tides and ocean mass variations (GOT4.7/ OMCT; Ray, 1999), atmospheric mass variations (ECMWF; Ray and Ponte, 2003), terrestrial water storage (GLDAS/Noah; Ek et al., 2003; Rodell et al., 2004) and glacial isostatic adjustment (GIA) and Little Ice Age correction (ICE-5G; Peltier, 2004) are employed in the L1B data processing in order to isolate land ice mass variations of interest, and in the case of forward hydrology modeling, limiting correlated residual signal contribution to the land ice solutions. Within Greenland, the absolute mass trend in each of these corrections is $<5 \mathrm{Gt} / \mathrm{a}$, and therefore small relative to the cryospheric mass trend $(<2 \%)$. For example, Luthcke et al. (2013) infer a GIA trend of $4.7 \pm 6.7 \mathrm{Gt} / \mathrm{a}$ integrated across all of Greenland during the 2003-2010 period. While GRACE-derived cryospheric mass balance products may detect larger seasonal snow loads than those predicted by numerical models such as GLDAS, employing a six hydrological year (i.e. September to October) mass and surface trend period reduces the influence of the seasonal cycle on underlying trends in cryospheric mass balance. Complete details on these forward models, individual trend magnitudes, and associated uncertainties are reported in Luthcke et al. (2013). Covariance constraints are applied by constraint region (e.g. Greenland ice sheet and oceans) in order to limit signal leakage in and out across region boundaries. The mascon solution is iterated until convergence, when nearly all signal is removed from the KBRR residuals (Luthcke et al., 2013). This iteration to minimize KBRR residuals is completely independent of the altimetryinformed iteration we describe here to locate mass variations in space.

Following L1B data reduction, the cryosphere-attributed linear mass trend and $1 \sigma$ trend error are calculated for each mascon time series and subsequently converted into equivalent spherical harmonics of degree/order (D/O) 60 via a set of differential potential coefficients ("delta coefficients") applied to the mean GRACE level 2 (L2) field (Chao et al., 1987; Luthcke et al., 2013). As the mass trend error estimate is assessed at the individual mascon level ( 110 $\mathrm{km}$ horizontal resolution), it yields a spatially variable error term that incorporates, statistical, signal leakage, atmospheric/oceanic modelling, and GIA modelling errors. In comparison to relatively sharp contrasts in mass change characteristic of mascon boundaries, the relatively smooth spatial gradients of spherical harmonics are better suited for the isotropic inversion filter we employ. We acknowledge that mascons ultimately provide a better inversion target than 
mascon-derived spherical harmonics, but we note that a mascon inversion requires an anisotropic geometric filter, and thus represents a non-trivial extension of the isotropic inversion we present.

\subsection{Altimetry-derived ice surface elevation trends}

The satellite altimetry-derived ice surface elevation trends and associated $1 \sigma$ uncertainty that we employ are based on ICESat observations collected during the Sep-2003 to Oct-2009 ICESat operational period (campaigns 2a to 2f). In the Canadian Arctic, ice surface elevation trends are derived from ICESat data following the method of Gardner et al. $(2011 ; 2012)$, whereby secular trends are assessed by fitting planar surfaces to $700 \mathrm{~m}$ repeat-tracks segments. In Greenland, ice surface elevation trends are derived from satellite and airborne altimetry data following the approach of Schenk and Csatho (2012), which corrects for intermission biases and glacial isostatic adjustment. While both the Greenland and Canadian Arctic ICESat observations have been corrected for detector saturation (Fricker et al., 2005), only the Canadian Arctic observations have been corrected for Gaussian-Centroid offset (Borsa et al., 2013). Although the absence of Gaussian-Centroid corrections can influence ice surface elevation trends by up to 2 $\mathrm{cm} / \mathrm{a}$, in our present work mass trends are ultimately constrained by gravimetry, and the cm-scale Gaussian-Centroid offset corrections have a minimal impact on the spatial variation of ice surface elevation trends (Section 5.1).

Hurkmans et al. (2012) suggest sparse altimetry sampling in the lower reaches of Jakobshavn Isbrae can result in ordinary space-time kriging underestimating basin-scale mass loss by up to $20 \%$, while larger discrepancies may be found further south on the Greenland ice sheet (Simonsen et al., 2015). Schenk and Csatho (2012) therefore supplement ICESat observations with airborne altimetry observations (Airborne Topographic Mapper (ATM) observations collected by NASA Operation IceBridge), when and where available, in an attempt to account for potential under sampling of the dynamic mass loss associated with major Greenland outlet glaciers. ATM data are especially critical in South Greenland, where ICESat ground tracks are located relatively far apart, and frequent cloud cover results in data gaps in the ICESat record. Unlike in Greenland, however, we do not supplement ICESat observations with airborne observations in the relatively high latitude Canadian Arctic. While the dynamic drawdown of outlet glaciers is an important mechanism of mass loss in Greenland, the majority of mass loss in the Canadian Arctic occurs via surface melt and runoff (Gardner et al., 2011). 
192 This decreases the likelihood that sparse altimetry sampling will under sample spatially

193 heterogeneous dynamic processes in the Canadian Arctic. Additionally, while airborne altimetry 194 observations were acquired over Greenland's outlet glaciers almost every year during the Sep1952003 to Oct-2009 study period, airborne altimetry was only collected in the Canadian Arctic in 1962005 during the study period, which does not permit assessing repeat airborne elevation trends 197 that approximate the ICESat operational period. We note that Gardner et al. (2011) similarly 198 omit airborne observations from their mass balance assessment of the Canadian Arctic, while 199 Gardner et al. (2012) adopt the time period between airborne surveys in order to incorporate 200 201 airborne observations into their mass balance assessment of the South Canadian Arctic.

Across both Greenland and the Canadian Arctic, where sufficient repeat observations are available, we interpolate irregularly spaced ice surface elevation trends into 2 by $2 \mathrm{~km}$ cells, rather than extrapolating observed ice surface elevation trends to all ice coverage using hypsometry relations. We then average all available $2 \mathrm{~km}$ resolution ice surface elevation trends within a given 26 by $26 \mathrm{~km}$ grid cell to assess the mean ice surface elevation trend at $26 \mathrm{~km}$ resolution. At grid cells with $100 \%$ ice fraction, this $26 \mathrm{~km}$ resolution ice surface elevation trend is derived from 169 individual trends assessed at $2 \mathrm{~km}$ resolution. In Greenland, an average of 141 values at $2 \mathrm{~km}$ resolution are used to calculate mean ice surface elevation trend at $26 \mathrm{~km}$ resolution. In the Canadian Arctic, where ice coverage seldom approaches $100 \%$ at $26 \mathrm{~km}$ resolution, an average of 36 values at $2 \mathrm{~km}$ resolution are used to calculate mean ice surface

$212 \mathrm{~km}$ resolution ice surface elevation trends within a $26 \mathrm{~km}$ resolution grid cell is characteristic of 213 the uncertainty in ice surface elevation trend at $26 \mathrm{~km}$ resolution. This assumption implies that 214 systematic errors in altimetry-derived ice surface elevation trend are smaller than the $26 \mathrm{~km}$ 215 scale spatial variability in ice surface elevation trend. The fundamental spatial correlation scale of ICESat elevation trend estimates is difficult to quantify because there are both observational 217 and natural spatial correlation in observed elevation changes. We effectively assume full 218 correlation within $2 \mathrm{~km}$ grid cells (which contain multiple repeat-tracks or airborne profiles) and no correlation between 2 km grid cells. For comparison, Gardner et al. $(2011 ; 2012)$ assume an 220 along-track correlation length of $5 \mathrm{~km}$ and no correlation between different sets of repeat-tracks. 221 We therefore suggest that our $1 \sigma$ standard deviation in ice surface elevation trends is roughly 
222 consistent with the uncertainty assessed in previous studies. We perform a sensitivity analysis on

223 the potential influence of firn compaction trends in Section 5.1.

224

225

226

227

228

229

230

231

232

233

234

235

236

237

238

239

240

241

242

243

244

245

246

247

248

249

250

251

252

\subsection{Mass balance evaluation data}

We compare local HIGA algorithm-inferred mass balance values with previously published mass balance observations collected in Greenland and the Canadian Arctic. Evaluating mass balance values inverted from satellite gravimetry against point-scale in situ observations remains somewhat novel (Bareletta et al., 2012; Su et al., 2015). We note that mass balance $(\dot{m})$ observations are distinct from surface mass balance $(\dot{b})$ observations, in that the former quantifies mass changes resulting from both surface and underlying ice dynamic processes, while the latter only quantifies mass changes resulting from surface processes. In comparison to in situ surface mass balance observations, in situ observations of entire ice column mass balance are relatively scarce due to their time-consuming nature. We consider in situ mass balance measurements made via three techniques: (i) the "coffee can" method, (ii) the strain network method, and (iii) repeat geodetic survey. After reviewing the available literature, we find forty previously published in situ mass balance measurements across the Canadian Arctic and Greenland (Table 1). We compare these in situ observations to algorithm-inferred point mass balance.

The coffee can method calculates rate of change in ice equivalent thickness as the sum of long term surface mass balance, vertical ice velocity, and subtle downslope movement during the measurement period. The unique aspect of the coffee can approach is correcting observed vertical velocity at the snow surface, with a direct measurement of firn compaction rate, in order to isolate vertical ice velocity at the firn-ice interface (Hamilton and Whillans, 2002; Burgess et al., 2008). The strain network method relies on combining observations of local strain rates with knowledge of ice thickness, in order to assess vertical ice velocity via mass continuity. Local mass balance is then calculated by differencing this vertical ice velocity from long term surface mass balance (Reeh and Gundestrup, 1985; Hvidberg et al., 1997; 2002; Burgess and Sharp, 2008). Finally, when mass balance is measured via repeat geodetic ground survey, changes in surface elevation are combined with knowledge of the density associated with elevation change to assess ice equivalent thickness changes (Jezek, 2011; Morris and Wingham, 2011; Stober et al., 2013; Appendix). 
In both the coffee can and strain network approaches, mass balance is essentially derived by differencing long term ice dynamics and long term surface mass balance $(\dot{b})$. The resultant mass balance $(\dot{m})$ is therefore characteristic of the past several decades preceding the observation period. Thus, we compare coffee can and strain network-derived mass balance values to algorithm-inferred mass balance values with the caveat that the latter reflect the Sep2003 to Oct-2009 study period, while the former reflect a longer multi-decadal value. Given a paucity of in situ data, however, we still include both coffee can and strain network-derived multi-decadal mass balance values in our validation attempt, if only to demonstrate that our 26 $\mathrm{km}$ resolution inferred mass balance values are reasonable. Unlike the coffee can and strain network methods, neither long term ice dynamic nor long term surface mass balance are invoked in the repeat geodetic method. Thus, transient mass balance are directly comparable to geodetically-derived mass balance observed over the same period.

\section{METHOD}

Here, we describe the inversion approach we adopt to iteratively solve for a single field (mass balance) that is simultaneously consistent with: (i) fractional ice coverage, (ii) cryosphereattributed mass trends, and (iii) ice surface elevation trends. Our approach, which is couched in a purely probabilistic framework, differs from the West Antarctic inversion presented by ZammitMangion et al. (2013), who simultaneously solve four inverted fields, (i) glacial isostatic adjustment, (ii) firn compaction, (iii) ice dynamics and (iv) surface mass balance, using a system of stochastic partial differential equations in a Bayesian framework. We acknowledge that simultaneously inverting a GIA field that is consistent with bedrock uplift observations is potentially a more robust GIA treatment than we adopt here, in which GIA is forward modelled within the GRACE product. Our approach is more analogous to that of Su et al. (2015), who use altimetry-derived ice surface elevation trends to improve the spatial resolution of gravimetryderived mass trends, and assume that inter-annual variability in firn compaction is negligible, thereby leaving the firn density associated with mass and elevation changes as a free parameter.

\subsection{Algorithm}

The inversion algorithm presented by Colgan et al. (2013) had a "nominal" spatial resolution of $26 \mathrm{~km}$. By introducing fractional ice coverage as the only new information to the 
284

285

286

287

288

289

290

291

292

293

GRACE interpretation, this previous inversion approach was only capable of constraining cryosphere-attributed mass trends to within irregularly ice-covered areas, and was not capable of distinguishing spatial heterogeneity in mass trends between adjacent ice containing nodes. Further independent information, capable of distinguishing mass trends between adjacent icecontaining nodes, is required to achieve "actual" $26 \mathrm{~km}$ resolution. The algorithm we present below addresses this need, by introducing additional information in the form of altimetry-derived ice surface elevation trends. Unlike prescribed spatial covariance matrices, or spatially autocorrelated pure gravimetry inversions, this additional information permits non-correlated mass balances at adjacent ice-containing nodes within irregularly-shaped ice-covered areas (Su et al., 2015).

In Colgan et al. (2013), gravimetry data are refined by introducing additional information in the form of fractional ice coverage through a Gauss-Seidel-type iterative update of a higher resolution $(26 \mathrm{~km})$ mass balance field $(\dot{m})$, according to:

$$
\dot{m}_{i j}^{k+1}=\dot{m}_{i j}^{k}+\Delta_{i j}^{k} R_{i j}^{k} F_{i j}
$$

Eq. 1

where $k$ denotes a given iteration and $i j$ are node indices in Cartesian coordinates. The iterative update term is the product of three terms: the difference between a Gaussian smoothed version of $\dot{m}_{i j}$ and the input GRACE-derived mass trend field $\left(\Delta_{i j}^{k}\right)$, a random number from a uniform distribution between 0 and 1 , which serves as a stochastic source $\left(R_{i j}^{k}\right)$, and finally independent information in the form of fractional ice coverage $\left(F_{i j}\right)$. The first two of these terms vary by both iteration and node, whereas the latter only varies by node. A given simulation is initialized with a random $\dot{m}_{i j}$ field, and then iteratively updated until convergence within a prescribed tolerance. In Monte Carlo fashion, a large number of simulations are performed, each of which renders a higher resolution $\dot{m}_{i j}$ field that is consistent with both gravimetry and ice coverage observations. These simulations are then averaged to yield an ensemble mean field.

In this study, we introduce further independent information, observed ice surface elevation trend, by adopting a successive over relaxation (SOR)-type parameter $\left(\omega_{\mathrm{ij}}\right)$ into the iterative update term (Kincaid, 2004): 
When $\omega>1$, SOR can accelerate the iterative convergence of a system of equations that approach their solution asymptotically, yielding substantial gains in computational efficiency. In contrast, when $\omega<1$, successive under relaxation can impart stability on the iterative convergence of otherwise oscillatory systems of equations. In the spirit of SOR, implementing a spatially variable $\omega_{\mathrm{ij}}$, rather than a scalar $\omega$, across the inversion domain permits inverted mass trends to be preferentially weighted to nodes with relatively high $\omega$ values, rather than nodes with relatively low $\omega$ values. As satellite altimetry is capable of resolving localized ice surface elevation trends that result from outlet glacier acceleration, altimetry-derived ice surface elevation trends provide a logical source of independent information for distinguishing between non-correlated mass balances at adjacent ice-containing nodes. Informing $\omega_{\mathrm{ij}}$ with observations of ice surface elevation trend allows cryosphere-attributed mass trends to be spatially distributed in a fashion that is consistent with ice surface elevation trends.

We generate a first-order spatially variable $\omega_{\mathrm{ij}}$ field from observed ice surface elevation trends according to:

$$
\omega_{i j}=\frac{\left|\dot{z}_{i j}\right|}{\left(\left|\dot{z}_{l j}\right|\right)}
$$

where $\dot{z}_{i j}$ is altimetry-derived ice surface elevation trend. This essentially computes $\omega_{\mathrm{ij}}$ as absolute normalized ice surface elevation trend (Figure 4); at a given node, $\omega$ is the local absolute ice surface elevation trend divided by the mean of all absolute ice surface elevation trends across the ten sectors of interest within the inversion domain. Assuming that mass trends are proportional to ice surface elevation trends, this parameter represents relative differences in mass trends across the domain. These trends are "relative", as $\omega$ has been normalized and enters the algorithm as a dimensionless term, rather than an absolute unit of elevation change.

We evaluate this SOR-type $\omega_{\mathrm{ij}}$ parameter at all ice-containing nodes within the inversion domain. We subsequently constrain extreme values of $\omega_{\mathrm{ij}}$. At nodes where calculated $\omega_{\mathrm{ij}}<1$, we

342 prescribe $\omega_{\mathrm{ij}}=1$ to prevent successive under relaxation. At the $<0.01 \%$ of nodes where calculated $\omega_{\mathrm{ij}}>10$, we prescribe $\omega_{\mathrm{ij}}=10$. These constraints allow the $\omega_{\mathrm{ij}}$ parameter representing 
relative differences in ice surface elevation trends to range over an order-of-magnitude across ice-containing nodes, while still maintaining numerical stability. For example, a ten times greater mass trend would be attributed to a node with $\omega=10$ than a neighboring node with $\omega=1$. Spatial gradients in $\omega$ acknowledge the reality that mass balance typically decreases to a minimum at the periphery of an ice mass. We similarly calculate uncertainty in this SOR-type parameter $\left(\delta \omega_{\mathrm{ij}}\right)$ as:

where $\sigma \dot{z}_{i j}$ is the $1 \sigma$ standard deviation of all observed ice surface elevation trends within node $i j$, and $\varepsilon$ is a small number (taken here as $0.1 \mathrm{~m} / \mathrm{a}$ ) to maintain numerical stability where $\dot{z}_{i j} \rightarrow 0$. This essentially assumes that local uncertainty in $\omega_{\mathrm{ij}}$ is directly proportional to local uncertainty in ice surface elevation trend. In each simulation $\omega_{\mathrm{ij}}$ is locally perturbed by the addition of $\delta \omega_{\mathrm{ij}} \cdot R_{\mathrm{ij}}$, where $R_{\mathrm{ij}}$ is a random number array that varies by node in each simulation.

We invert a 1000 simulation ensemble of GRACE-derived cryosphere-attributed mass trends. In each simulation within this ensemble, the GRACE-derived spherical harmonic representation $\left(\dot{M}^{G}\right)$ is randomly perturbed within its associated error $\left(\delta \dot{M}^{G}\right)$, to yield a unique $\dot{M}^{G}+\delta \dot{M}^{G}$ input field. A given Monte Carlo simulation is initialized with a spatially variable $\dot{m}_{i j}$ field, comprised of an array of random numbers uniformly distributed between -100 and $+100 \mathrm{~kg} / \mathrm{m}^{2} / \mathrm{a}$ that has been multiplied by fractional ice area $\left(F_{i j}\right)$. This initial $\dot{m}_{i j}$ field varies over the same order of magnitude as the anticipated final $\dot{m}_{i j}$ field, and thus minimizes hysteresis resulting from prescribed initial conditions (Colgan et al., 2013). Beginning with this initial condition, the higher resolution $(26 \mathrm{~km})$ mass balance field $(\dot{m})$ is iteratively updated, following Eq. 2, until convergence. In each iteration of each simulation the difference between the input $\dot{M}^{G}$ and the Gaussian-smoothed $\dot{m}$ field $(\dot{M})$ is randomly perturbed according to $\Delta_{i j}^{k} R_{i j}^{k}$ in Eq. 2. We adopt a convergence criterion of $0.1 \mathrm{Gt} / \mathrm{a}$ and an isotropic Gaussian scaling length of $200 \mathrm{~km}$, as suggested by our previous sensitivity analysis of gravimetry inversion (Colgan et al., 2013).

\subsection{Boundaries}


In the US National Snow and Ice Data Center (NSIDC) polar stereographic projection,

375 the inversion domain we employ extends from $-1625 \mathrm{~km}$ in the west to $1300 \mathrm{~km}$ in the east, and

376 from $-125 \mathrm{~km}$ in the north to $-3800 \mathrm{~km}$ in the south (Figure 1). We employ a uniform grid

377 spacing of $26 \mathrm{~km}$, which results in 113 computational nodes along the Easting axis and 142

378 computational nodes along the Northing axis, for a total of 16046 computational nodes within

379 the model domain. This grid spacing resolution is the highest resolution that allows the isotropic

380 Gaussian filter node-specific dimensionless weighting values to be stored as a single three

381 dimensional array of $113 \cdot 142 \cdot 16046$ elements on the per processor RAM available on the

382 University of Colorado's Janus Supercomputer. The polar stereographic projection introduces

383 increasing distortion away from its central meridian $\left(45^{\circ} \mathrm{W}\right)$ and parallel $\left(70^{\circ} \mathrm{N}\right)$, which

384 influences area calculations. We compensate for area distortion by calculating the true area of

385 each individual node across the domain $\left(A_{i j}\right)$. The true areas of ice-containing nodes vary

386 between $24.5^{2}$ and $27.5^{2} \mathrm{~km}^{2}$ over the domain.

387 By employing a spherical harmonic representation of cryosphere-attributed mass trend

$388\left(\dot{M}^{G}\right)$, the mass balances associated with non-ice containing nodes are theoretically negligible

389 (e.g. $\dot{m}=0 \mathrm{~kg} / \mathrm{m}^{2} / \mathrm{a}$ where $F=0$ ). Practically, however, mass balances at non-ice containing

390 nodes are not truly zero, but rather within uncertainty of zero (e.g. $\dot{m} \approx 0 \mathrm{~kg} / \mathrm{m}^{2} / \mathrm{a}$ where $F=0$ ).

391 Following a sensitivity study by Colgan et al. (2013), we prescribe a non-ice containing node

392 absolute threshold $\left(\dot{m}_{\max }\right)$ of $15 \mathrm{~kg} / \mathrm{m}^{2} / \mathrm{a}$. Simply put, this permits the inversion to assign

393 between -15 and $+15 \mathrm{~kg} / \mathrm{m}^{2} / \mathrm{a}$ of mass change at non-ice containing nodes. The mass trend

394 uncertainty at non-ice containing nodes acknowledged by this boundary condition is

395 representative of the level of uncertainty typically assessed for GRACE-derived spherical

396 harmonic solutions (e.g. Velicogna and Wahr, 2005; Longuevergne et al., 2010), and an order of

397 magnitude less than the $\dot{m}_{i j}$ values inferred by the inversion at adjacent ice-containing nodes.

398 This boundary condition is implemented at non-ice containing nodes according to a Heaviside, or

399 logic, function invoked to appropriately modify Eq. 2 where $F=0$ (Colgan et al., 2013).

400

401

\subsection{Uncertainty}

402

The probabilistic inversion algorithm described above acknowledges multiple sources of

403 uncertainty with stochastic terms. Random numbers are used to: (i) globally perturb the input

404 GRACE-derived spherical harmonic trend within its associated uncertainty in each simulation, 
(ii) locally perturb the SOR-type introduction of surface elevation trend within its associated uncertainty in each simulation, and (iii) sufficiently perturb local update terms in each iteration to overcome initial condition hysteresis (Eq. 2). Together, these stochastic inclusions ensure that inferred mass balance is not spatially correlated (i.e. subject to a covariance matrix), and enhances the algorithm's ability to efficiently explore the infinite number of possible solutions (e.g. Colgan et al., 2012). The mean fractional uncertainty we assume in the SOR-type parameter $(\delta \omega)$ exceeds 0.7 in the Canadian Arctic, while it remains below 0.2 in Greenland (Figure 4). This contrast in the uncertainty associated with altimetry-informed $\omega$ in Canada and Greenland effectively acknowledges differences in airborne data availability and sampling, as well as ice hypsometries, between both regions. Random uncertainty in point mass balance $\left(\delta \dot{m}_{\text {ran }}\right)$ is estimated as the $2 \sigma$ ensemble spread in inferred $\dot{m}_{i j}$ values across the 1000 simulations at a given node. Random uncertainty in sector scale mass balance is similarly estimated as the $2 \sigma$ ensemble spread in inferred mass balance across the 1000 simulations within a given sector (Table 2). While intentionally opposing covariance in mass trends between adjacent computational nodes prevents constraining the density associated with change by an a priori length scale distribution (e.g. Zammit-Mangion et al., 2013), the resulting random uncertainty in point mass balance estimated via ensemble spread is an order of magnitude larger than typical uncertainties in mass balance due to changes in firn density or firn compaction rate ( $\mathrm{Li}$ and Zwally, 2011).

While the above sources of uncertainty are stochastic (or random) by definition and implementation, additional systematic (or bias) uncertainty is associated with the inverted mass balance via the Gibbs truncation phenomenon (or "ringing effect"; Swenson and Wahr, 2002). By virtue of using a $200 \mathrm{~km}$ an isotropic Gaussian scaling length, a non-trivial mass trend signal weight is contained beyond $\mathrm{D} / \mathrm{O} 60$. Thus, ringing results from a difference in the effective $\mathrm{D} / \mathrm{O}$ of the GRACE-derived spherical harmonic mass trend (D/O 60) and the Gaussian-smoothed inverted field which is effectively D/O 100. As we are reluctant to increase the $\mathrm{D} / \mathrm{O}$ of the inverted GRACE-derived mass trend solution above its fundamental resolution of 60, and computing spherical harmonics to subsequently truncate at D/O 60 in each iteration of each simulation is computationally intractable, we cannot eliminate ringing. We therefore acknowledge ringing as an additional source of systematic uncertainty. The potential bias in mass trend associated with ringing is estimated by differencing a D/O 100 spherical harmonic 
solution of the ensemble mean from an analogous spherical harmonic solution that has been truncated at D/O 60. This difference field reflects the non-trivial noise and signal contained in D/O 61 through 100 (Figure 5). The absolute difference field is taken to represent systematic uncertainty in point mass balance $\left(\delta \dot{m}_{s y s}\right)$. At sector scale, unlike random uncertainty, systematic uncertainty is integrated across all nodes within a given sector (Table 2). At both point and sector scale, total uncertainty $(\delta \dot{m})$ is taken as the quadratic sum of random and systematic uncertainties. While systematic uncertainty is less than random uncertainty at point scale, at sector scale cumulative systematic uncertainty is greater than random uncertainty (Figure 6). We simply sum sector scale uncertainties to assess Greenland-wide uncertainty. As a substantial portion of total uncertainty is most likely independent between sectors, this substantially overestimates actual uncertainty at ice sheet scale.

\section{RESULTS}

\subsection{Evaluation against point mass balance observations}

We expect HIGA algorithm inferred mass balance values to be accurate, within associated $2 \sigma$ uncertainty, at $26 \mathrm{~km}$ resolution. We evaluate inferred point mass balance against forty previously published in situ mass balance measurements across Greenland and the Canadian Arctic (Table 1; Figure 2). At nodes where ice coverage is less than $100 \%$, we correct algorithm inferred mass balance per unit area to equivalent mass balance per unit ice-covered area using fractional ice coverage. Of these forty in situ measurements, there are eighteen for which the majority of the in situ observation period falls within the Sep-2003 to Oct-2009 study period. We find a root mean squared error (RMSE) of $0.15 \mathrm{mWE} / \mathrm{a}$ between HIGA-inferred and in situ mass balances, with 37 of forty (or $93 \%$ ) in situ versus HIGA-inferred mass balance comparisons within error of $y=x$ (Figure 7). The spatial distribution of residuals suggests that the algorithm generally overestimates mass balances observed along the West Greenland geodetic transect of Morris and Wingham (2011), and underestimates mass balances observed elsewhere, primarily by coffee can and strain network approaches (Reeh and Gundestrup, 1985; Hvidberg et al., 1997; 2002; Hamilton and Whillans, 2002; Burgess and Sharp, 2008; Figure 8). We therefore speculate that a portion of the apparent discrepancy between in situ and algorithminferred mass balances may be attributable to changes in high elevation surface mass balance between the historical period captured by longer term coffee can or strain network observations, 
and the contemporary period captured by shorter term geodetic observations (Vaughan et al., 2013). While the nature of cryospheric research often necessitates that large scale remotely sensed data products are evaluated against sparse in situ observations, with a component of discrepancy conventionally attributed to local noise (e.g. Stroeve et al., 2013), the small number of in situ observations presently available prevent this RMSE from serving as an independent assessment of the absolute accuracy of HIGA-inferred point mass balance. We suggest instead that this evaluation exercise merely demonstrates that HIGA-inferred point mass balance values compare well to available observations. Perhaps the overarching message of this evaluation attempt is that there is an urgent need for in situ Greenland mass balance measurements in regions of high mass loss and on peripheral glaciers. The HIGA spatial mass balance product that we evaluate here, as well as its associated uncertainty, is available in the supplementary material associated with this publication.

\subsection{Hybrid inversion mass balance estimates}

Of the ten geographic sectors we examine across Greenland and the Canadian Arctic, only one (Sector 2 in Northeast Greenland) is within error of zero balance (Table 3). The remaining nine sectors are clearly in negative balance, resulting in a total ice loss of $292 \pm 87$ Gt/a across Greenland and the Canadian Arctic over the Sep-2003 to Oct-2009 study period. The inversion suggests a mass loss of $212 \pm 67 \mathrm{Gt} / \mathrm{a}$ from the ice sheet proper, a mass loss of $38 \pm 11$ $\mathrm{Gt} / \mathrm{a}$ from Greenland peripheral glaciers, and a mass loss of $42 \pm 11 \mathrm{Gt} / \mathrm{a}$ from the Canadian Arctic. Peripheral glaciers in Greenland and glaciers in Canada therefore account for $80 \pm 22$ Gt/a (or $\sim 27 \%$ ) of the total regional mass loss we assess. These estimates of mass loss are ultimately dependent on the GRACE-derived spherical harmonic representation we employ (Luthcke et al., 2013). Within Greenland, peripheral glaciers contribute the greatest mass loss in Sector 3 (12 $\pm 4 \mathrm{Gt} / \mathrm{a})$, which includes the abundant peripheral glaciers surrounding the Geikie Plateau, and the least mass loss in Sector $2(0 \pm 0 \mathrm{Gt} / \mathrm{a})$, which is in relatively arid Northeast Greenland. Mass loss from the ice sheet proper is greatest in Sectors 3 (45 $\pm 13 \mathrm{Gt} / \mathrm{a}$ in East Greenland) and 8 (43 \pm 12 Gt/a in Northwest Greenland), where large tidewater glaciers are present. While apparent ringing artifacts are evident in the Canadian Arctic, the potential bias stemming from the Gibbs phenomenon is acknowledged in our formal uncertainty estimates (Table 2; Figure 6). We note that Colgan et al. (2013) previously misattributed anomalously 
positive mass balance values on south Baffin Island to unidentified oceanic mass changes not captured in the forward ocean model used to isolate cryospheric mass loss, rather than ringing artifacts.

While the total ice sheet and peripheral glacier mass losses presented here are similar to those derived by the pure gravimetry inversion of Colgan et al. $(2013 ; 218 \pm 20 \mathrm{Gt} / \mathrm{a}$ and $34 \pm 5$ Gt/a, respectively, over the Dec-2003 to Dec-2010 period), the HIGA approach provides a substantial improvement in characterizing the spatial distribution of mass balance and uncertainty in mass balance. Indeed, virtually identical domain-integrated mass balance estimates, but with different spatial patterns between both approaches, attests to satisfying gravimetry-observed mass trends with and without satisfying the additional independent information of altimetry-observed volume trends. While pure gravimetry inversions typically yield gentle spatial gradients in mass balance across ice covered areas, by assuming that local mass trends are proportional to local ice surface elevation trends, the HIGA mass balance product contains a spatially heterogeneous mass balance field (Figure 9; c.f. Barletta et al., 2013; Colgan et al., 2013). The HIGA mass balance product assigns relatively more mass loss at Greenland tidewater outlet glaciers, where relatively rapid dynamic drawdown is occurring, in comparison to a pure gravimetry inversion. This increased peripheral mass loss is offset by decreased mass loss further inland on the ice sheet, which effectively results in a higher mass balance gradient with distance inland or with elevation (Figure 10).

\subsection{Comparison against previous mass balance estimates}

We place our mass balance estimates within ten geographic sectors in the context of eleven previously published mass balance estimates and their associated uncertainties (Zwally et al., 2005; 2011; Luthcke et al., 2006; Gardner et al., 2011; 2012; Schrama and Wouters, 2011; Jacob et al., 2012; Sasgen et al., 2012; Barletta et al., 2013; Andersen et al., 2015; Nilsson et al., 2015). We limit this comparison to previously published studies that provide sector-scale mass balance estimates (c.f. Enderlin et al., 2014). We note that these assessments estimate mass balance through various input-output, altimetry and gravimetry approaches, with reported uncertainties varying between $1 \sigma$ and $2 \sigma$, as well as unspecified, confidence (Figure 11). The formal uncertainty of any study appears to be substantially smaller than inter-study discrepancies, even considering differences in methodology and time period, which may suggest 
that spatially compensating errors partially underlie the apparent agreement of diverse mass loss estimates at ice sheet scale. While the suite of mass balance estimates to which we compare exhibits a minimum inter-study scatter of c. $30 \mathrm{Gt} / \mathrm{a}$ in Sectors 2 and 9, they exhibit a maximum inter-study scatter of c. $90 \mathrm{Gt} / \mathrm{a}$ in Sector 4 . Sector 4 is presumably especially sensitive to differing methodologies due to the combination of: (i) relatively high ice dynamic thinning and surface mass balance rates, which can present challenges when correcting altimetry observations for firn processes, and (ii) a relatively high ice sheet margin to area ratio, which can spatially bias the anomalies observed by satellite gravimetry and increase the influence of downstream flux gate corrections applied to input-output assessments.

The sector-scale HIGA mass balance estimates we present are within uncertainty of previous estimates, including the pure gravimetry inversion of Barletta et al. (2013), in all sectors in Greenland and the Canadian Arctic. Many previous studies have consolidated some or all of the eight major Greenland sectors (Luthcke et al., 2006; Jacob et al., 2012; Sasgen et al., 2012; Barletta et al., 2013). For example, while seven previous studies assess the mass balance of Sector 8 proper, only four previous studies assess the mass balance of Sector 6 proper (which is often merged with Sector 7). While there is no apparent bias in our HIGA mass balance product relative to conventional gravimetry, altimetry or input-output assessments in North, East and South Greenland (Sectors 1 to 5) and the Canadian Arctic (Sectors 9 and 10), our hybrid gravimetry-altimetry product appears biased towards underestimating mass loss in West Greenland (Sectors 6 to 8) relative to the input-output approach (Andersen et al., 2015). We note, however, that the input-output assessment of Andersen et al. (2015) appears to form an upper limit of estimated mass loss in these three sectors across all studies. As the Andersen et al. (2015) mass loss assessment is within uncertainty of similar, but entirely independent, inputoutput approaches at ice sheet scale, this may suggest that input-output approaches overestimate mass loss in West Greenland (Rignot et al., 2011; Enderlin et al., 2014).

The mass loss we assess to the Canadian Arctic ( $42 \pm 11 \mathrm{Gt} / \mathrm{a})$ is significantly less than the $60 \pm 8 \mathrm{Gt} / \mathrm{a}$ assessed by Gardner et al. (2013) over the comparable Oct-2003 to Oct-2009 period, but within uncertainty of the $50 \pm 22 \mathrm{Gt} / \mathrm{a}$ assessed by Nilsson et al. (2015) over the same period, as well as the lesser $33 \pm 22 \mathrm{Gt} / \mathrm{a}$ assessed by Schrama and Wouters (2011) over the Mar2003 to Feb-2010 period. Given that the HIGA inferred estimate of Canadian Arctic mass balance that we present is bounded by the pure altimetry approach of Gardner et al. (2013) and 
the pure gravimetry approach of Schrama and Wouters (2011), the apparent discrepancy may well stem from differing assumptions and corrections between methodologies, which make the Canadian Arctic relatively sensitive to mass loss over- and under-estimation by altimetry and gravimetry, respectively. The mass loss we attribute to Greenland peripheral glaciers $(38 \pm 11$ $\mathrm{Gt} / \mathrm{a}$ ) is consistent with the previous Bolch et al. (2013) both CLO+1 and CLO+1+2 estimates of $28 \pm 11$ and $44 \pm 18 \mathrm{Gt} / \mathrm{a}$, respectively, over the Oct-2003 to Mar-2008 period*, as well as the 38 \pm 7 Gt/a estimate of Gardner et al. (2013) over the Oct-2003 to Oct-2009 period. Our estimate that peripheral glaciers presently comprise $\sim 15 \%$ of Greenland's ice loss is within the analogous 14 to $20 \%$ range estimated by Bolch et al. (2013). Given that our peripheral glacier area is more similar to the CL0+1 scenario of Bolch et al. (2013) than the CL0+1+2 scenario, as well as similar to the area used by Garner et al. (2013), we infer more negative specific mass balances than Bolch et al. (2013), but similar specific mass balances to Gardner et al. (2013). The regional distribution of our peripheral glacier mass loss is within uncertainty (or at least overlapping uncertainty) of both these previous studies in Sectors 1, 3, 4+5, 6 and 8 (Table 4). In Sector 2 (Northeast Greenland), we assess significantly less mass loss $(0 \pm 0 \mathrm{Gt} / \mathrm{a}$ rather than $0.6 \pm 0.3$ to $2.8 \pm 1.0 \mathrm{Gt} / \mathrm{a})$, while in Sector 7 we assess significantly more mass loss $(5 \pm 1 \mathrm{Gt} / \mathrm{a}$ rather than $1.0 \pm 0.4$ to $2.4 \pm 1.3 \mathrm{Gt} / \mathrm{a}$ ). Although differing firn compaction corrections are likely the chief source of difference between the altimetry-derived Bolch et al. (2013) and Gardner et al. (2013) studies, we speculate our apparent bias in Sector 7 peripheral glacier mass loss may stem from spatial aliasing of gravimetry anomalies in the vicinity of Jakobshavn.

Overall, this sector-scale evaluation suggests that our sector-scale HIGA-inferred mass balance estimates of Greenland ice sheet sectors, Canadian Arctic glaciers and Greenland peripheral glacier sectors appear reasonable in the context of previous published values.

* We note that while Bolch et al. (2013) state a CL0+1+2 mass loss of $41 \pm 16 \mathrm{Gt} / \mathrm{a}$ in their abstract, the regional values in their Table 2 sum to $-44 \pm 18 \mathrm{Gt} / \mathrm{a}$. T. Bolch (personnel communication, 2014) confirms the latter is correct.

\section{DISCUSSION}

\subsection{Firn densification}


Altimetry observations are conventionally used to assess mass balance via the conversion of observed volume change into inferred mass change, using a forward modelled density of change (Sorensen et al., 2011; Zwally et al., 2011). In this conventional approach, the density of change is "known" while the mass change is "unknown". In an inversion approach, by contrast, gravimetry-derived mass change is "known" while the density of change remains "unknown" (Su et al., 2015). This residual density of change incorporates both firn density, as well as the rate of change in firn density (or firn compaction rate). A potential outcome of the multiple physical mechanisms contained in this residual density is that effective densities of change can become larger than ice densities, or even negative ( Li and Zwally, 2011; Huss, 2013). Although ZammitMangion et al. (2013) leave firn compaction as a free parameter, they prescribe a firn compaction covariance length scale via a prior distribution in their Bayesian approach. In contrast, we do not prescribe a priori covariance distributions for any parameter in our probabilistic approach, including the effective density associated with volume change. Similar to Su et al. (2015), we do not correct altimetry-derived ice surface elevation trends for firn processes, but in contrast to $\mathrm{Su}$ et al. (2015), we use dimensionless normalized ice surface elevation trends to guide the distribution of gravimetry-derived mass trends across ice-covered nodes. We are content using ice surface elevation trends to guide the fingerprint of our mass trend inversion, rather than firncorrected elevation trends, as: (i) firn compaction is primarily driven by changes in air temperature and accumulation, both of which vary over spatial scales greater than the $26 \mathrm{~km}$ grid resolution we adopt (Zwally et al., 2011), (ii) changes in ice surface elevation trends with distance are an order of magnitude greater than the change in firn compaction rates with distance across the Greenland ice sheet.

We validate this assumption with a sensitivity analysis, in which we apply a forward modelled firn densification correction to observed ice surface elevation trends. We subtract the firn compaction (or firn air content) trend corresponding to the Sep-2003 to Oct-2009 study period, from observed ice surface elevation trends on a node-by-node basis above equilibrium line attitude. This previously developed fifteen year lagging firn compaction trend is forward modelled using HIRHAM5 regional climate model (RCM) air temperature, precipitation and melt water forcing at a nominal horizontal resolution of $5 \mathrm{~km}$ (Sørensen et al., 2011; LucasPicher et al., 2012). The model firn column is sampled only at ICESat epochs, to replicate the discontinuous sampling in the ICESat elevation record. We bilinearly interpolate this $5 \mathrm{~km}$ firn 
compaction trend to the $26 \mathrm{~km}$ resolution of our inversion domain. While the decreasing firn compaction (or firn air content) trend exceeds $5 \mathrm{~cm} / \mathrm{a}$ in Southeast Greenland, it is less than 1 $\mathrm{cm} / \mathrm{a}$ across the majority of the ice sheet (Figure 12). The Sørensen et al. (2011) firn product does not cover the Canadian Arctic, where we assume firn compaction trends are negligible for the purposes of this sensitivity analysis. While correcting ice surface elevation trends for firn compaction trends modifies the spatial distribution of the SOR-type parameter $\left(\omega_{\mathrm{ij}}\right)$ used in the iterative update (Eq. 2), this influence is extremely subtle. The HIGA-inferred mass balance field derived from firn-corrected ice surface trends typically differs from the analogous field derived from raw ice surface trends by $<25 \mathrm{~kg} / \mathrm{m}^{2} / \mathrm{a}$ (Figure 12). This is substantially less than the difference in point mass balance derived from pure gravimetry and HIGA inversions (Figure 10), and also substantially less than the local uncertainty in mass balance we assess based on the quadratic sum of random and systematic uncertainties (Figure 6). The spatially integrated difference in mass balance resulting from introducing the firn compaction trend correction is less than $0.1 \mathrm{Gt} / \mathrm{a}$ in all sectors. We therefore contend that the assumption that ice surface elevation trends can be used to guide the fingerprint of mass trends is valid ( $\mathrm{Su}$ et al., 2015), and removes the need for introducing additional uncertainty associated with the RCM and firn models.

\subsection{Spatial partition of the continuity equation}

The mass balance $(\dot{m})$ at any point on a glacier or ice sheet is the difference between surface mass balance $(\dot{b})$ and the horizontal divergence of ice flux $(\nabla Q)$, as described by the transient glacier continuity equation:

$$
\dot{m}=\dot{b}-\nabla Q
$$

Eq. 5

We use $\dot{m}$ in place of conventional $\dot{H}$ in the above formulation of the transient glacier continuity equation (c.f. Paterson, 1994). As the left-hand term in Eq. 5 represents net mass changes due to both climatic surface forcing and divergence of ice flux, when averaged over the entire ice column thickness it may be regarded as either a "mass balance rate $(\dot{m})$ " or a "rate of change in ice equivalent thickness $(\dot{H})^{\prime}$. Differencing the HIGA-inferred mass balance $(\dot{m})$ presented above from an independently modelled surface mass balance $(\dot{b})$ allows the ice dynamic portion of mass balance to be solved as a spatial residual (Figure 13). 
We employ modelled surface mass balance over the Sep-2003 to Oct-2009 study period

653 from the regional climate model MAR (version 3.3) forced with ERA-Interim reanalysis data

654 along the lateral boundaries (Fettweis et al., 2013). This MAR-derived surface mass balance field

655 is available over Greenland and the Canadian Arctic at $15 \mathrm{~km}$ resolution. Following the

656 identification of an accumulation bias in MAR (version 2.1), which resulted in an RMSE of $46 \%$

$657(24 \%)$ with point surface mass balance observations above (below) $1500 \mathrm{~m}$ elevation (Vernon et

658 al., 2013), MAR (version 3.0+) has been tuned with 86 spatially distributed ice core-derived

659 accumulation records (Box et al., 2013). MAR (version 3.3) reproduces local surface mass

660 balance observations with an RMSE of $\sim 20 \%$, and ice sheet wide net surface mass balance with

661 an uncertainty of $\sim 10 \%$ (Fettweis et al., 2013; Colgan et al., 2015). Thus, for the purposes of

662 partitioning the transient continuity equation at $26 \mathrm{~km}$ resolution, we take uncertainty in MAR-

663 derived local surface mass balance $\pm 20 \%(\delta \dot{b}$; to a minimum of $0.1 \mathrm{mWE} / \mathrm{a})$. Solving $\nabla Q$ as a

664 residual inherently compounds the uncertainties in both $\dot{b}$ and $\dot{m}$, which we sum in quadrature to

665 calculate $\delta(\nabla Q)$ (Figure 14). Given the difficulties associated with estimating divergence of ice

666 flux from either first principles numerical modelling or remotely sensed observations, we suggest

667 that there is value in solving transient divergence of ice flux as a residual, despite the relatively

668 high consequent uncertainty, which exceeds $1 \mathrm{mWE} / \mathrm{a}$ near the terminus of Jakobshavn Isbrae.

669 The residual ice flux field generally exhibits divergence (e.g. positive $\nabla Q$ values)

670 throughout the ice sheet interior and convergence (e.g. negative $\nabla Q$ values) around the ice sheet

671 periphery (Figure 13). This is notionally consistent with negative (submerging) vertical ice

672 velocities in the ice sheet accumulation area, and positive (emerging) vertical ice velocities in the

673 ice sheet ablation area. Closer inspection, however, reveals contrasting ice dynamic signatures of

674 predominately marine-terminating portions of the ice sheet (e.g. Southeast Greenland and Geikie

675 Plateau) and predominately land-terminating portions of the ice sheet (e.g. North Greenland and

676 Southwest Greenland). In land-terminating regions there is a wide band of convergent (or

677 emergent) ice flux along the ice sheet periphery, while in marine-terminating regions the ice flux

678 is divergent (or submergent) to the ice margin. This is broadly consistent with the first principles

679 continuum mechanics notion that convergent flux counters surface ablation in land-terminating

680 regions, while divergent flux supplies iceberg discharge in marine-terminating regions.

681 Given a paucity of major tidewater outlet glaciers, mass loss in the Canadian Arctic is

682 primarily driven by surface mass balance (Gardner et al., 2011; Lenearts et al., 2013; van 
Wychen et al., 2014). We therefore also compare HIGA-inferred spatial mass balance with MAR modelled spatial surface mass balance in the Canadian Arctic. We find a weak positive correlation between inferred $\dot{m}$ and modelled $\dot{b}$ at $26 \mathrm{~km}$ resolution $(\mathrm{p}<0.05, \mathrm{r}=0.27$ and $\mathrm{df}=$ 66; Figure 15). While this is notionally consistent with $\dot{b}$ driving $\dot{m}$, the relatively poor correlation $\left(\mathrm{RMSE}=430 \mathrm{~kg} / \mathrm{m} /{ }^{2}\right.$ a) reflects the combined uncertainties associated with both HIGA-inferred mass balance and MAR modelled surface mass balance, as well as difficulties associated with relatively coarse remote sensing and modelling approaches being employed to capture cryospheric processes in a region with complex glacier hypsometries. We speculate that regressing $\dot{m}$ and $\dot{b}$ at higher spatial resolutions would be expected to substantially improve the apparent correlation of $\dot{m}$ with $\dot{b}$. Lenaerts et al. (2013) suggest that spatial resolutions of < 10 $\mathrm{km}$ are needed to resolve the complex hypsometry of glaciers in the Canadian Arctic. MAR (version 3.3) surface mass balance is presently available at $15 \mathrm{~km}$ resolution over the Canadian Arctic, which is insufficient to resolve distinct ablation and accumulation areas. Complementary mass balance assessments of the Canadian Arctic have generally tended to produce areaintegrated sector-scale estimates, rather than gridded products, making our $26 \mathrm{~km}$ product one of the highest resolution gridded mass balance products to date.

\section{SUMMARY REMARKS}

The mass balance product that we derive through a probabilistic iterative inversion is simultaneously consistent with glacier inventory derived from optical imagery, cryosphereattributed mass trends derived from satellite gravimetry, and ice surface elevation trends derived from airborne and satellite altimetry. This Hybrid glacier Inventory, Gravimetry and Altimetry (HIGA) product combines the complementary strengths of gravimetry and altimetry to refine direct measurements of cryosphere-attributed mass trends to $26 \mathrm{~km}$ spatial resolution. We have evaluated local algorithm inferred mass balance values against forty in situ observations. We caution that the resulting RMSE of $0.15 \mathrm{mWE} / \mathrm{a}$ cannot serve as an independent estimate of HIGA inversion accuracy for point mass balance, given differing observation periods and a paucity of in situ observations from regions of high dynamic mass loss and peripheral glaciers. Our comparison of area-integrated mass balance estimates in ten sectors in Greenland and the Canadian Arctic with analogous estimates in eleven previous studies suggests that HIGA inferred mass balance estimates are reasonable in the context of other methods. Sector scale 
disagreements suggest that spatially compensating errors may underlie apparent agreement in estimates of total Greenland mass balance. Generally, however, the mass losses we assess in Greenland and the Canada Arctic are consistent with previously published estimates. Given that Greenland's peripheral glaciers, which comprise $<5 \%$ of Greenland's ice covered area, appear to be contributing $15 \%$ of the total Greenland mass loss ultimately constrained by satellite gravimetry, GRACE-derived estimates of "Greenland" mass loss cannot reasonably be taken as synonymous with "Greenland ice sheet" mass loss.

Unlike a conventional forward model altimetry approach to assessing ice sheet mass balance, in the inversion framework we implement the ultimate mass change is "known" while the density of change is "unknown" (rather than vice versa). We perform a sensitivity analysis in which correct raw ice surface elevation trends for firn compaction (or firn air content) trends, and find that the HIGA-inferred mass balance field is relatively insensitive to whether or not ice surface elevation trends are corrected for firn processes. In contrast, whether or not altimetry information is included in an otherwise pure gravimetry inversion results in a substantial difference in inferred point mass balance values. We therefore contend that the assumption that ice surface elevation trends can be used to guide the fingerprint of mass trends is valid. Differencing HIGA-inferred mass balance from MAR modelled surface mass balance permits divergence of ice flux (or "ice dynamics") to be calculated as a residual, and therefore effectively partition the transient glacier continuity equation at $26 \mathrm{~km}$ resolution across Greenland and the Canadian Arctic during the Sep-2003 to Oct-2009 study period. This partition reveals divergent flux (or submerging flow) in the ice sheet accumulation area and along tidewater margins, and convergent flux (or emerging flow) in land-terminating ice sheet ablation areas, which is broadly consistent with the first principles of glacier continuum mechanics.

\section{ACKNOWLEDGEMENTS}

This work was funded by NASA award NNX10AR76G and DFF award FNU 11-115166. This work utilized the Janus supercomputer, which is supported by NSF award CNS-0821794 and the University of Colorado Boulder. The Janus supercomputer is a joint effort of the University of Colorado Boulder, the University of Colorado Denver and the National Center for Atmospheric Research. W.C. thanks Joel Frahm for his continued assistance working with Janus. M.C. was supported by PROMICE and GlacioBasis with funds from the Danish Energy Agency. 
We thank Ken Jezek for sharing his field data and reviewing our interpretation of the mass balance of the Ohio State University clusters in South Greenland. We also thank two anonymous reviewers, whose insightful comments greatly improved this manuscript. Dorothy Hall served as our dedicated scientific editor.

\section{APPENDIX}

\section{A.1. Jezek (2011) geodetic observations}

While 36 of the forty in situ mass balance observations we have compiled express mass balance in either water or ice equivalent rate of thickness change, the geodetic observations of Jezek (2011) examine elevation, rather than mass, changes across the Ohio State University (OSU) cluster of geodetic stakes in the South Greenland accumulation area. Here, we convert those observations of surface elevation trend into mass trend using knowledge of near surface firn density. The mass of a given ice column $(m)$ may be described as the product of its density $(\rho)$ and thickness $(H)$ :

$$
m=\rho H
$$

Given that both density and thickness are dependent on time (e.g. $\rho(t)$ and $H(t)$ ), it follows from the Leibniz or product rule that the transient rate of mass change, or mass balance, of a given ice column $(\dot{m})$ may be described as:

$$
\dot{m}=\dot{\rho} H+\rho \dot{H}
$$

where the first term can be interpreted as primarily describing mass changes within the firn column (e.g. changes in density of known thickness), and the second term can be interpreted as primarily describing mass changes within the underlying ice column (e.g. changes in thickness of known density). Fortunately, both firn cores and firn density modelling provide insight on the rate of change in firn density $(\dot{\rho})$ at the OSU central cluster. Near surface (15 m deep) density profiles from the OSU central cluster suggest $\dot{\rho}=-3.8 \mathrm{~kg} / \mathrm{m}^{3} / \mathrm{a}$ over the 1981 to 1993 period (Jezek, 2012). Over the 2003 to 2007 period, firn modeling suggests a slight densification of 83

\footnotetext{
$\mathrm{kg} / \mathrm{m}^{2} / \mathrm{a}$, equivalent to $\dot{\rho}=5.5 \mathrm{~kg} / \mathrm{m}^{3} / \mathrm{a}$ if distributed over a $15 \mathrm{~m}$ firn column (Zwally et al.,
} 
2011). Jezek (2011) suggests that the changes in ice sheet elevation observed at the OSU clusters are most consistent with independent flux-gate estimations of mass change when the effective density of elevation change is taken as ice density, and thus when changes in near-surface density are assumed to be small (e.g. $\dot{\rho} \approx 0$ ). We therefore assume $\dot{\rho}=0 \pm 5 \mathrm{~kg} / \mathrm{m}^{3} / \mathrm{a}$ when converting observations of surface elevation trend into mass balance at the OSU clusters (Table A1). This uncertainty approximates the range of contrasting firn densification rates derived from in situ and model approaches.

\section{A.2. Previous peripheral glacier estimates}

While Bolch et al. (2013) peripheral glacier mass balance within thirteen regions of Greenland, Gardner et al. (2013) produce analogous estimates within nine regions. Neither previous study use the major sectors employed in our present study (Zwally et al., 2012). We must therefore assume that geographic extent of some regions in these previous studies are, or can be aggregated into regions, broadly consistent with those of Zwally et al. (2012). Neither previous study, however, sufficiently delineates between Sectors 4 and 5. We therefore only aggregate peripheral glacier mass balance estimates into seven sectors, with Sectors 4 and 5 being grouped together as "Sector 4+5" (Table 4). We assume the following sector aggregations for Bolch et al. (2013): 1 = north central, 2 = north east, 3 = east north + east central + east south, $4+5=$ south east, $6=$ south west, $7=$ west central, and $8=$ west north + north west. For Gardner et al. (2013), we assume: 1 = north central + Flade Isblink, 2 = north east, 3 = Foster/Scoresby, 4 $+5=$ Denmark Strait + south east, $6=$ south west, $7=$ Disko/Melville, and $8=$ north west.

\section{LITERATURE CITED}

Alley, R., M. Spencer and S. Anandakrishnan. 2007. Ice-sheet mass balance: assessment, attribution and prognosis. Annals of Glaciology. 46: 1-7.

Andersen, M., L. Stenseng, H. Skourup, W. Colgan, S. Khan, S. Kristensen, S. Andersen, J. Box, A. Ahlstrøm, X. Fettweis and R. Forsberg. 2015. Basin-scale partitioning of Greenland ice sheet mass balance components (2007-2011). Earth and Planetary Science Letters. 409: 89-95.

Arendt, A., A. Bliss, T. Bolch, J.G. Cogley, A.S. Gardner, J.O. Hagen, R. Hock, M. Huss, G. Kaser, C. Kienholz, W.T. Pfeffer, G. Moholdt, F. Paul, V. Radić, L. Andreassen, S. 
Bajracharya, N. Barrand, M. Beedle, E. Berthier, R. Bhambri, I. Brown, E. Burgess, D. Burgess, F. Cawkwell, T. Chinn, L. Copland, B. Davies, H. De Angelis, E. Dolgova, K. Filbert, R. Forester, A. Fountain, H. Frey, B. Giffen, N. Glasser, S. Gurney, W. Hagg, D. Hall, U.K. Haritashya, G. Hartmann, C. Helm, S. Herreid, I. Howat, G. Kapustin, T. Khromova, M. König, J. Kohler, D. Kriegel, S. Kutuzov, I. Lavrentiev, R. LeBris, J. Lund, W. Manley, C. Mayer, E.S. Miles, X. Li, B. Menounos, A. Mercer, N. Mölg, P. Mool, G. Nosenko, A. Negrete, C. Nuth, R. Pettersson, A. Racoviteanu, R. Ranzi, P. Rastner, F. Rau, B. Raup, J. Rich, H. Rott, C. Schneider, Y. Seliverstov, M. Sharp, O. Sigurðsson, C. Stokes, R. Wheate, S. Winsvold, G. Wolken, F. Wyatt, N. Zheltyhina. 2014. Randolph Glacier Inventory - A Dataset of Global Glacier Outlines: Version 4.0. GLIMS Technical Report. Available at www.glims.org/RGI/00_rgi40_TechnicalNote.pdf Barletta, V., L. Sørensen and R. Forsberg. 2013. Scatter of mass changes estimates at basin scale for Greenland and Antarctica. The Cryosphere. 7: 1411-1432.

Bolch, T., L. Sandberg Sørensen, S. Simonsen, N. Mölg, H. Machguth, P. Rastner and F. Paul. 2013. Mass loss of Greenland's glaciers and ice caps 2003-2008 revealed from ICESat laser altimetry data. Geophysical Research Letters. 40: 875-881.

Borsa, A., G. Moholdt, H. Fricker and K. Brunt. 2013. A range correction for ICESat and its potential impact on ice sheet mass balance studies. The Cryosphere Discussions. 7: 42874319. doi:10.5194/tcd-7-4287-2013.

Box, J., N. Cressie, D. Bromwich, J. Jung, M. van den Broeke, J. van Angelen, R. Forster, C. Miege, E. Mosley-Thompson, B. Vinther and J. McConnell. 2013. Greenland ice sheet mass balance reconstruction. Part I: net snow accumulation (1600-2009). Journal of Climate. 26: 3919-3934.

Burgess, D., and M. Sharp. 2008. Recent changes in thickness of the Devon Island ice cap, Canada. Journal of Geophysical Research. 113, B07204: doi:10.1029/2007JB005238.

Chao, B., W. O'Connor, A. Chang, D. Hall and J. Foster. 1987. Snow load effect on the Earth's rotation and gravitational field, 1979-1985. Journal of Geophysical Research. 92(B9), 9415-9422.

Citterio, M. and A. Ahlstrøm. 2013. Brief communication "The aerophotogrammetric map of Greenland ice masses". The Cryosphere. 7: 445-449, doi:10.5194/tc-7-1-2013. 
Colgan, W., W. Pfeffer, H. Rajaram, W. Abdalati and J. Balog. 2012. Monte Carlo ice flow modeling projects a new stable configuration for Columbia Glacier, Alaska, c. 2020. The Cryosphere. 6: 1395-1409. doi:10.5194/tc-6-1395-2012.

Colgan, W., S. Luthcke, W. Abdalati and M. Citterio. 2013. Constraining GRACE-derived cryosphere-attributed signal to irregularly shaped ice-covered areas. The Cryosphere. 7: 1901-1914. doi:10.5194/tc-7-1901-2013.

Colgan, W., J. Box, M. Andersen, X. Fettweis, B. Csatho, R. Fausto, D. van As and J. Wahr. 2015. Greenland high-elevation mass balance: inference and implication of reference period (1961-90) imbalance. Annals of Glaciology. 56: 105-117.

Enderlin, E., I. Howat, S. Jeong, M. Noh, J. van Angelen and M. van den Broeke. 2014. An improved mass budget for the Greenland ice sheet. Geophysical Research Letters. 41: doi:10.1002/2013GL059010.

Ek, M., K. Mitchell, Y. Lin, E. Rogers, P. Grunmann, V. Koren, G. Gayno and J. Tarpley. 2003. Implementation of Noah land surface model advances in the National Centers for Environmental Prediction operational mesoscale Eta model. Journal of Geophysical Research. 108, 8851. doi: 10.1029/2002JD003296.

Fettweis, X., B. Franco, M. Tedesco, J. van Angelen, J. Lenaerts, M. van den Broeke and H. Gallée. 2013. Estimating the Greenland ice sheet surface mass balance contribution to future sea level rise using the regional atmospheric climate model MAR. The Cryosphere: 7: 469-489.

Fricker, H., A. Borsa, B. Minster, C. Carabajal, K. Quinn K and B. Bills. 2005. Assessment of ICESat performance at the Salar de Uyuni, Bolivia. Geophysical Research Letters. 32: L21S06, doi:10.1029/2005GL023423.

Gardner, A., G. Moholdt, B. Wouters, G. Wolken, D. Burgess, M. Sharp, J. Cogley, C. Braun and C. Labine. 2011. Sharply increased mass loss from glaciers and ice caps in the Canadian Arctic Archipelago. Nature. 473: 357-360.

Gardner, A., G. Moholdt, A. Arendt and B. Wouters. 2012. Accelerated contributions of Canada's Baffin and Bylot Island glaciers to sea level rise over the past half century. The Cryosphere. 6: 1103-1125.

Gardner, A., G. Moholdt, J. Cogley, B. Wouters, A. Arendt, J. Wahr, E. Berthier, R. Hock, W. Pfeffer, G. Kaser, S. Ligtenberg, T. Bolch, M. Sharp, J. Hagen, M. van den Broeke, and 
F. Paul. 2013. A Reconciled Estimate of Glacier Contributions to Sea Level Rise: 2003 to 2009. Science. 340: 852-857.

Hamilton, G. and I. Whillans. 2002. Local rates of ice-sheet thickness change in Greenland. Annals of Glaciology. 35: 79-83.

Hurkmans, R., J. Bamber, L. Sørensen, I. Joughin, C. Davis and W. Krabill. 2012. Spatiotemporal interpolation of elevation changes derived from satellite altimetry for Jakobshavn Isbræ, Greenland. Journal of Geophysical Research. 117: F03001.

Huss, M. 2013. Density assumptions for converting geodetic glacier volume change to mass change. The Cryosphere. 7: 877-887.

Hvidberg, C., K. Keller, N. Gundestrup, C. Tscherning and R. Forsberg. 1997. Mass balance and surface movement of the Greenland Ice Sheet at Summit, central Greenland. Geophysical Research Letters. 24: 2307-2310.

Hvidberg, C., K. Keller and N. Gundestrup. 2002. Mass balance and ice flow along the northnorthwest ridge of the Greenland ice sheet at NorthGRIP. Annals of Glaciology. 35: 521526.

Jacob, T., J. Wahr, W. Pfeffer and S. Swenson. 2012. Recent contributions of glaciers and ice caps to sea level rise. Nature. 482: 514-518.

Jezek, K. 2011. Surface elevation and velocity changes on the south-central Greenland ice sheet: 1980-2011. Journal of Glaciology. 58: 1201-1211.

Jezek, K. 2012. Surface Elevation and Velocity Changes on the South Central Greenland Ice Sheet: 1980-2011 Data Summary. BPRC Technical Report No. 2012-01. Byrd Polar Research Center, The Ohio State University, Columbus, Ohio. 28 pages plus data summary. Available at: https://kb.osu.edu/dspace/bitstream/handle/1811/53654/BPRC_TechReport_2012_01.pdf

Khan, S., J. Wahr, M. Bevis, I. Velicogna and E. Kendrick. 2010. Spread of ice mass loss into northwest Greenland observed by GRACE and GPS. Geophysical Research Letters. 37: L06501.

Kincaid, D. 2004. Celebrating Fifty Years of David M. Young's Successive Overrelaxation Method. Numerical Mathematics and Advanced Applications. M. Feistauer, V. Dolejsi, P. Knoblock and K. Najzar. Springer Berlin Heidelberg. 549-558. doi:10.1007/978-3642-18775-9 
Lenaerts, J., J. van Angelen, M. van den Broeke, A. Gardner, B. Wouters and E. van Meijgaard. 2013. Irreversible mass loss of Canadian Arctic Archipelago glaciers. Geophysical Research Letters. 40: 870-874.

Li, J. and H. Zwally. 2011. Modeling of firn compaction for estimating ice-sheet mass change from observed ice-sheet elevation change. Annals of Glaciology. 52: 1-7.

Longuevergne, L., B. Scanlon and C. Wilson. 2010. GRACE Hydrological estimates for small basins: Evaluating processing approaches on the High Plains Aquifer, USA. Water Resources Research. 46: W11517, doi:10.1029/2009WR008564.

Lucas-Picher, P., Wulff-Nielsen, M., Christensen, J. H., Adalgeirsdóttir, G., Mottram, R. H., \& Simonsen, S. B. 2012. Very high resolution regional climate model simulations over Greenland: Identifying added value. Journal of Geophysical Research, 117: 2108.

Luthcke, S., H. Zwally, W. Abdalati, D. Rowlands, R. Ray, R. Nerem, F. Lemoine, J. McCarthy and D. Chinn. 2006. Recent Greenland Ice Mass Loss by Drainage System from Satellite Gravity Observations. Science. 314: 1286-1289.

Luthcke, S., T. Sabaka, B. Loomis, A. Arendt, J. McCarthy and J. Camp. 2013. Antarctica, Greenland and Gulf of Alaska land-ice evolution from an iterated GRACE global mascon solution. Journal of Glaciology. 59: 613-631.

Morris, E. and D. Wingham. 2011. The effect of fluctuations in surface density, accumulation and compaction on elevation change rates along the EGIG line, central Greenland. Journal of Glaciology. 57: 416-430.

Nilsson, J., L. Sandberg Sørensen, V. Barletta and R. Forsberg. 2015. Mass changes in Arctic ice caps and glaciers: implications of regionalizing elevation changes. The Cryosphere. 9: 139-150.

Paterson, W. 1994. The physics of glaciers: Steady flow of glaciers and ice sheets. Third Edition. Butterworth-Heinemann. London, UK.

Peltier, W. 2004. Global glacial isostatic adjustment and the surface of the ice-age Earth: the ICE-5G(VM2) model and GRACE. Annual Reviews Earth Planetary Science. 32: 111149. doi: 10.1146/annurev.earth.32.082503.144359.

Pfeffer, W., A. Arendt, A. Bliss, T. Bolch, J. Cogley, A. Gardner, J. Hagen, R. Hock, G. Kaser, C. Kienholz, E. Miles, G. Moholdt, N. Mölg, F. Paul, V. Radic, P. Rastner, B. Raup, J. 
Rich, M. Sharp and The Randolph Consortium. 2014. The Randolph Glacier Inventory: a globally complete inventory of glaciers. Journal of Glaciology. 60: 537-551.

Rastner, P., T. Bolch, N. Mölg, H. Machguth and F. Paul. 2012. The first complete glacier inventory for the whole of Greenland. The Cryosphere. 6: 1483-1495. doi:10.5194/tc-61483-2012.

Ray, R. 1999. A global ocean tide model from TOPEX/Poseidon altimetry/GOT99.2. NASA Tech. Rep. NASA/TM-1999-209478. NASA Goddard Space Flight Center, Greenbelt, MD.

Ray, R. and R. Ponte. 2003. Barometric tides from ECMWF operational analyses. Annales Geophysicae. 21: 1897-1910.

Reeh, N. 1985. Was the Greenland ice sheet thinner in the late Wisconsinan than now? Nature. 317: 797-799.

Reeh, N., and N. Gundestrup. 1985. Mass balance of the Greenland Ice Sheet at Dye-3. Journal of Glaciology. 31: 198-200.

Rignot, E., J. Box, E. Burgess and E. Hanna. 2008. Mass balance of the Greenland ice sheet from 1958 to 2007. Geophysical Research Letters. 35: L20502.

Rignot, E., I. Velicogna, M. van den Broeke, A. Monaghan and J. Lenaerts. 2011. Acceleration of the contribution of the Greenland and Antarctic ice sheets to sea level rise. Geophysical Research Letters. 38: L05503.

Rodell, M., P. Houser, U. Jambor, J. Gottschalck, K. Mitchell, C. Meng, K. Arsenault, B. Cosgrove, J. Radakovich, M. Bosilovich, J. Entin, J. Walker, D. Lohmann, and D. Toll. 2004. The global land data assimilation system. Bulletin of the American Meteorological Society. 85: 381-394. doi: 10.1175/BAMS-85-3-381.

Sasgen, I., M. van den Broeke, J. Bamber, E. Rignot, L. Sørensen, B. Wouters, Z. Martinec, I. Velicogna and S. Simonsen. 2012. Timing and origin of recent regional ice-mass loss in Greenland. Earth and Planetary Science Letters. 333-334, 293-303.

Schenk, T. and B. Csatho. 2012. A New Methodology for Detecting Ice Sheet Surface Elevation Changes From Laser Altimetry Data. Geoscience and Remote Sensing, IEEE Transactions. 50: 3302-3316.

Schrama, E. and B. Wouters. 2011. Revisiting Greenland ice sheet mass loss observed by GRACE. Journal of Geophysical Research. 116: B02407, doi:10.1029/2009JB006847. 
Shepherd, A., E. Ivins, A. Geruo, V. Barletta, M. Bentley, S. Bettadpur, K. Briggs, D. Bromwich, R. Forsberg, N. Galin, M. Horwath, S. Jacobs, I. Joughin, M. King, J. Lenaerts, J. Li, S. Ligtenberg, A. Luckman, S. Luthcke, M. McMillan, R. Meister, G. Milne, J. Mouginot, A. Muir, J. Nicolas, J. Paden, A. Payne, H. Pritchard, E. Rignot, H. Rott, L. Sørensen, T. Scambos, B. Scheuchl, E. Schrama, B. Smith, A. Sundal, J. van Angelen, W. van de Berg, M. van den Broeke, D. Vaughan, I. Velicogna, J. Wahr, P. Whitehouse, D. Wingham, D. Yi, D. Young, and H. Zwally. 2012. A Reconciled Estimate of Ice-Sheet Mass Balance. Science. 338: 1183-119.

Simonsen, S., Barletta, V., Forsberg, R., \& Sandberg Sørensen, L. 2015. Reconciled freshwater flux into the Godthåbsfjord system from satellite and airborne remote sensing. International Journal of Remote Sensing. doi:10.1080/01431161.2014.995277

Sørensen, L., S. Simonsen, K. Nielsen, P. Lucas-Picher, G. Spada, G. Adalgeirsdottir, R. Forsberg and C. Hvidberg. 2011. Mass balance of the Greenland ice sheet (2003-2008) from ICESat data - the impact of interpolation, sampling and firn density. The Cryosphere. 5: 173-186.

Stober, M., P. Rawiel, J. Hepperle and R. Wössner. 2013. Long-term observations (1991-2011) of elevation change and ice flow velocity in the Swiss-Camp area (West Greenland). IASC-NAG Workshop: The Dynamics and Mass Budget of Arctic Glaciers. Geological Survey of Denmark and Greenland Report 3: 68-72.

Stroeve, J.C., J.E. Box, Z. Wang, C. Schaaf, A. Barrett. 2013. Re-evaluation of MODIS MCD43 Greenland albedo accuracy and trends. Remote Sensing of Environment. 138: 199-214.

Su, X., C. Shum, J. Guo, J. Duan, I. Howat and Y. Yi. 2015. High resolution Greenland ice sheet inter-annual mass variations combing GRACE gravimetry and Envisat altimetry. Earth and Planetary Science Letters. 422: 11-17.

Swenson, S. and J. Wahr. 2002. Methods for inferring regional surface-mass anomalies from Gravity Recovery and Climate Experiment (GRACE) measurements of time-variable gravity. Journal of Geophysical Research. 107: B9, 2193.

van den Broeke, M., J. Bamber, J. Ettema, E. Rignot, E. Schrama, W. van de Berg, E. van Meijgaard, I. Velicogna and B. Wouters. 2009. Partitioning Recent Greenland Mass Loss. Science. 326: 984-986. 
van Wychen, W., D. Burgess, L. Gray, L. Copeland, M. Sharp, J. Dowdeswell and T. Benham. 2014. Glacier velocities and dynamic ice discharge from the Queen Elizabeth Islands, Nunavut, Canada. Geophysical Research Letters. 41: doi:10.1002/2013GL058558.

Vaughan, D., J. Comiso, I. Allison, J. Carrasco, G. Kaser, R. Kwok, P. Mote, T. Murray, F. Paul, J. Ren, E. Rignot, O. Solomina, K. Steffen and T. Zhang. 2013. Observations: Cryosphere. In Climate Change 2013: The Physical Science Basis. Contribution of Working Group I to the Fifth Assessment Report of the Intergovernmental Panel on Climate Change Edited by T. Stocker, D. Qin, G. Plattner, M. Tignor, S. Allen, J. Boschung, A. Nauels, Y. Xia, V. Bex and P. Midgley. Cambridge University Press, Cambridge, UK and New York, NY, USA

Velicogna, I. and J. Wahr. 2005. Greenland mass balance from GRACE. Geophysical Research Letters. 32: L18505, doi:10.1029/2005GL023955.

Vernon, C., J. Bamber, J. Box, M. van den Broeke, X. Fettweis, E. Hanna and P. Huybrechts. 2013. Surface mass balance model intercomparison for the Greenland ice sheet. The Cryosphere. 7: 599-614.

Wu, X., Heflin, M. B., Schotman, H., Vermeersen, B. L. A., Dong, D., Gross, R. S., ... Owen, S. E. (2010). Simultaneous estimation of global present-day water transport and glacial isostatic adjustment. Nature Geoscience. 3: 642-646.

Zammit-Mangion, A., J. Rougier, J. Bamber and N. Schon. 2013. Resolving the Antarctic contribution to sea-level rise: a hierarchical modelling framework. Environmetrics. 24: doi:10.1002/env.2247.

Zwally, H., M. Giovinetto, J. Li, H. Cornejo, M. Beckley, A. Brenner, J. Saba and D. Yi. 2005. Mass changes of the Greenland and Antarctic ice sheets and shelves and contributions to sea-level rise: 1992-2002. Journal of Glaciology. 51: 509-527.

Zwally, H., J. Li, A. Brenner, M. Beckley, H. Cornejo, J. DiMarzio, M. Giovinetto, T. Neumann, J. Robbins, J. Saba, D. Yi and W. Wang. 2011. Greenland ice sheet mass balance: distribution of increased mass loss with climate warming; 2003-07 versus 1992-2002. Journal of Glaciology. 57: 88-102.

Zwally, H., M. Giovinetto, M. Beckley and J. Saba. 2012. Antarctic and Greenland Drainage Systems. NASA GSFC Cryospheric Sciences Laboratory. Available online: 
1020

1021

1022

http://icesat4.gsfc.nasa.gov/cryo_data/ant_grn_drainage_systems.php. Accessed: 3 December 2013. 


\section{TABLES}

Table 1 - Previously published in situ mass balance $(\dot{m})$ measurements throughout Greenland and the Canadian Arctic; listed by observation period. Coffee can (C), strain network (S) and geodetic $(\mathrm{G})$ techniques are denoted under method. Asterisks $(*)$ denote sites where the majority of the in situ observation period falls within the Sep-2003 to Oct-2009 study period. Site locations shown in Figure 2.

\begin{tabular}{|c|c|c|c|c|c|c|c|}
\hline Site & ID & ${ }^{\circ} \mathbf{N}$ & ${ }^{\circ} \mathbf{E}$ & $\dot{m}$ (mWE/a) & Period & Method & Ref \\
\hline Dye-3 & 4 & 65.18 & -43.83 & $0.03 \pm 0.06$ & c. $1883-1983$ & $S$ & 1 \\
\hline Summit & 27 & 72.57 & -38.45 & $-0.03 \pm 0.04$ & c. $1956-1996$ & $S$ & 2 \\
\hline NGRIP & 32 & 75.08 & -42.32 & $0.00 \pm 0.04$ & C. $1788-2001$ & $S$ & 3 \\
\hline South Dome & 1 & 63.15 & -44.82 & $0.122 \pm 0.208$ & c. $1950-2000$ & C & 4 \\
\hline Saddle & 7 & 66.00 & -44.50 & $0.073 \pm 0.184$ & c. $1950-2000$ & C & 4 \\
\hline Dye-2 & 8 & 66.50 & -46.27 & $0.081 \pm 0.166$ & c. $1950-2000$ & C & 4 \\
\hline Crawford Point & 11 & 69.88 & -46.97 & $-0.419 \pm 0.239$ & c. $1950-2000$ & C & 4 \\
\hline Daugaard-Jensen & 25 & 71.88 & -32.05 & $-0.281 \pm 0.204$ & c. $1950-2000$ & C & 4 \\
\hline Summit & 27 & 72.57 & -38.45 & $0.036 \pm 0.021$ & c. $1950-2000$ & C & 4 \\
\hline NASA-U & 29 & 73.83 & -49.50 & $-0.022 \pm 0.146$ & c. $1950-2000$ & C & 4 \\
\hline NASA-E & 30 & 75.00 & -30.00 & $0.061 \pm 0.090$ & c. $1950-2000$ & C & 4 \\
\hline Camp Century & 35 & 77.24 & -61.03 & $-0.194 \pm 0.172$ & c. $1950-2000$ & C & 4 \\
\hline Humboldt & 36 & 78.53 & -56.83 & $0.021 \pm 0.069$ & c. $1950-2000$ & C & 4 \\
\hline Devon 1 & 34 & 75.34 & -82.68 & $0.03 \pm 0.04$ & c. $1967-2007$ & S & 5 \\
\hline Devon 2 & 33 & 75.18 & -82.78 & $-0.05 \pm 0.05$ & c. $1967-2007$ & $S$ & 5 \\
\hline Devon 3 & 31 & 75.01 & -82.88 & $-0.23 \pm 0.07$ & c. $1967-2007$ & S & 5 \\
\hline Devon 1 & 34 & 75.34 & -82.68 & $-0.02 \pm 0.03$ & c. $1967-2007$ & C & 5 \\
\hline Devon 2 & 33 & 75.18 & -82.78 & $-0.11 \pm 0.05$ & c. $1967-2007$ & C & 5 \\
\hline Devon 3 & 31 & 75.01 & -82.88 & $0.04 \pm 0.06$ & c. $1967-2007$ & C & 5 \\
\hline Dye-3 Divide & 2 & 64.85 & -44.65 & $0.046 \pm 0.075$ & $1980-2011$ & $G$ & 6 \\
\hline Dye-3 East & 5 & 65.26 & -43.47 & $-0.055 \pm 0.075$ & $1980-2011$ & $G$ & 6 \\
\hline${ }^{*}$ OSU West & 6 & 65.39 & -47.67 & $-0.153 \pm 0.075$ & $2005-2011$ & $\mathrm{G}$ & 6 \\
\hline *OSU Central & 3 & 65.11 & -45.69 & $-0.015 \pm 0.075$ & 2005-2011 & $G$ & 6 \\
\hline${ }^{*} \mathrm{~T} 12$ & 12 & 70.18 & -45.34 & $-0.02 \pm 0.23$ & 2004-2006 & $\mathrm{G}$ & 7 \\
\hline *T15 & 13 & 70.3 & -44.57 & $0.25 \pm 0.23$ & 2004-2006 & $G$ & 7 \\
\hline${ }^{*} \mathrm{~T} 19$ & 14 & 70.47 & -43.56 & $-0.06 \pm 0.22$ & 2004-2006 & $G$ & 7 \\
\hline${ }^{*} \mathrm{~T} 21$ & 15 & 70.54 & -43.02 & $-0.13 \pm 0.26$ & 2004-2006 & $\mathrm{G}$ & 7 \\
\hline${ }^{*} \mathrm{~T} 21 \mathrm{~A}$ & 16 & 70.59 & -42.79 & $0.01 \pm 0.17$ & 2004-2006 & $\mathrm{G}$ & 7 \\
\hline${ }^{*} \mathrm{~T} 23$ & 17 & 70.63 & -42.58 & $-0.06 \pm 0.16$ & 2004-2006 & $\mathrm{G}$ & 7 \\
\hline${ }^{*} \mathrm{~T} 27$ & 18 & 70.78 & -41.54 & $-0.04 \pm 0.13$ & 2004-2006 & $G$ & 7 \\
\hline${ }^{*} \mathrm{~T} 31$ & 19 & 70.91 & -40.64 & $-0.03 \pm 0.22$ & 2004-2006 & $\mathrm{G}$ & 7 \\
\hline${ }^{*}$ T35 & 20 & 70.98 & -39.55 & $0.06 \pm 0.23$ & 2004-2006 & $G$ & 7 \\
\hline${ }^{*}$ T39 & 21 & 71.04 & -38.46 & $0.06 \pm 0.13$ & 2004-2006 & $\mathrm{G}$ & 7 \\
\hline${ }^{*} \mathrm{~T} 41$ & 22 & 71.08 & -37.92 & $0.18 \pm 0.25$ & 2004-2006 & $G$ & 7 \\
\hline${ }^{*} \mathrm{~T} 41 \mathrm{~A}$ & 23 & 71.26 & -37.85 & $0.15 \pm 0.23$ & 2004-2006 & $G$ & 7 \\
\hline${ }^{\star} \mathrm{T} 41 \mathrm{~B}$ & 24 & 71.61 & -37.71 & $0.00 \pm 0.25$ & 2004-2006 & $\mathrm{G}$ & 7 \\
\hline${ }^{*} \mathrm{~T} 41 \mathrm{C}$ & 26 & 71.97 & -37.57 & $0.06 \pm 0.21$ & 2004-2006 & $\mathrm{G}$ & 7 \\
\hline
\end{tabular}




\begin{tabular}{|l|c|c|c|c|c|c|c|}
\hline${ }^{*}$ T41D & 28 & 72.58 & -37.42 & $-0.05 \pm 0.25$ & $2004-2006$ & G & 7 \\
*Swiss Camp & 10 & 69.67 & -49.43 & $-0.79 \pm 0.04$ & $2004-2011$ & G & 8 \\
*ST2 & 9 & 69.58 & -49.78 & $-0.94 \pm 0.05$ & $2004-2011$ & G & 8 \\
\hline
\end{tabular}

1030

1031

1032

1033

1034

1035

1036

1037

1038

1039

1040

${ }^{\mathrm{I}}$ Reeh and Gundestrup, 1985

${ }^{2}$ Hvidberg et al., 1997

${ }^{3}$ Hvidberg et al., 2002

${ }^{4}$ Hamilton and Whillans, 2002

${ }^{5}$ Burgess and Sharp, 2008

${ }^{6}$ Jezek, 2011 (Appendix)

${ }^{7}$ Morris and Wingham, 2011

${ }^{8}$ Stober et al., 2013 
1041 Table 2 - Sector scale total $2 \sigma$ uncertainty in HIGA inferred mass balance, taken as the quadratic 1042 sum of random and system uncertainties. Random $2 \sigma$ uncertainty results from the stochastic 1043 inversion, while systematic uncertainty results from "ringing" or spherical harmonic solution 1044 truncation bias.

\begin{tabular}{|c|c|c|c|}
\hline Sector & $\begin{array}{c}\text { Random } \\
\text { Uncertainty } \\
\text { (Gt/a) }\end{array}$ & $\begin{array}{c}\text { Systematic } \\
\text { Uncertainty } \\
\text { (Gt/a) }\end{array}$ & $\begin{array}{c}\text { Total } \\
\text { Uncertainty } \\
\text { (Gt/a) }\end{array}$ \\
\hline $\mathbf{1}$ & \pm 5 & \pm 7 & \pm 9 \\
$\mathbf{2}$ & \pm 2 & \pm 6 & \pm 6 \\
$\mathbf{3}$ & \pm 10 & \pm 14 & \pm 17 \\
$\mathbf{4}$ & \pm 2 & \pm 8 & \pm 9 \\
$\mathbf{5}$ & \pm 2 & \pm 5 & \pm 6 \\
$\mathbf{6}$ & \pm 3 & \pm 8 & \pm 8 \\
$\mathbf{7}$ & \pm 2 & \pm 11 & \pm 12 \\
$\mathbf{8}$ & \pm 4 & \pm 12 & \pm 13 \\
$\mathbf{9}$ & \pm 4 & \pm 4 & \pm 6 \\
$\mathbf{1 0}$ & \pm 4 & \pm 2 & \pm 5 \\
\hline Total & \pm 39 & \pm 78 & \pm 87 \\
\hline
\end{tabular}

1045 1046 1047 1048 1049

Table 3 - HIGA-inferred mass balance in ten sectors across Greenland and the Canadian Arctic, partitioned into ice sheet and glacier contributions, with associated total $2 \sigma$ uncertainty (from Table 1).

\begin{tabular}{|c|c|c|c|}
\hline Sector & $\begin{array}{c}\text { Ice Sheet } \\
\text { (Gt/a) }\end{array}$ & $\begin{array}{c}\text { Glaciers } \\
\text { (Gt/a) }\end{array}$ & $\begin{array}{c}\text { Total } \\
\text { (Gt/a) }\end{array}$ \\
\hline $\mathbf{1}$ & $-20 \pm 7$ & $-5 \pm 3$ & $-25 \pm 9$ \\
$\mathbf{2}$ & $2 \pm 6$ & $0 \pm 0$ & $2 \pm 6$ \\
$\mathbf{3}$ & $-45 \pm 13$ & $-12 \pm 4$ & $-56 \pm 17$ \\
$\mathbf{4}$ & $-27 \pm 8$ & $-6 \pm 1$ & $-33 \pm 9$ \\
$\mathbf{5}$ & $-24 \pm 5$ & $-5 \pm 1$ & $-29 \pm 6$ \\
$\mathbf{6}$ & $-34 \pm 8$ & $-2 \pm 1$ & $-36 \pm 8$ \\
$\mathbf{7}$ & $-23 \pm 10$ & $-5 \pm 1$ & $-27 \pm 12$ \\
$\mathbf{8}$ & $-43 \pm 12$ & $-3 \pm 1$ & $-47 \pm 13$ \\
$\mathbf{9}$ & $0 \pm 0$ & $-24 \pm 6$ & $-24 \pm 6$ \\
$\mathbf{1 0}$ & $0 \pm 0$ & $-18 \pm 5$ & $-18 \pm 5$ \\
\hline Total & $-212 \pm 67$ & $-80 \pm 22$ & $-292 \pm 87$ \\
\hline
\end{tabular}


Table 4 - Comparison of HIGA-inferred Greenland peripheral glacier mass balance estimates presented here ("This Study") with previously published estimates in seven major sectors. Previously published estimates aggregated to sector-scale according to Appendix A.2.

\begin{tabular}{|c|c|c|c|c|}
\hline Sector & This Study & \multicolumn{2}{|c|}{ Bolch et al. (2013) } & \multirow{2}{*}{$\begin{array}{c}\text { Gardner et } \\
\text { al. (2013) }\end{array}$} \\
\cline { 3 - 4 } & & CL0+1 & CL0+1+2 & $-4.0 \pm 2.6$ \\
$\mathbf{1}$ & $-5 \pm 3$ & $-3.9 \pm 1.7$ & $-3.9 \pm 1.7$ & -4.0 \\
$\mathbf{2}$ & $0 \pm 0$ & $-0.6 \pm 0.3$ & $-0.7 \pm 0.3$ & $-2.8 \pm 1.0$ \\
$\mathbf{3}$ & $-12 \pm 4$ & $-9.9 \pm 4$ & $-20.2 \pm 8.1$ & $-10.3 \pm 2.5$ \\
$\mathbf{4 + 5}$ & $-11 \pm 2$ & $-7 \pm 2.9$ & $-11.3 \pm 4.6$ & $-12.3 \pm 4.8$ \\
$\mathbf{6}$ & $-2 \pm 1$ & $-3.3 \pm 1.4$ & $-3.4 \pm 1.4$ & $-2.6 \pm 1.3$ \\
$\mathbf{7}$ & $-5 \pm 1$ & $-1 \pm 0.4$ & $-1.0 \pm 0.4$ & $-2.4 \pm 1.3$ \\
$\mathbf{8}$ & $-3 \pm 1$ & $-2.2 \pm 0.8$ & $-3.3 \pm 1.3$ & $-3.2 \pm 0.8$ \\
\hline Total & $-38 \pm 12$ & $-27.9 \pm 11.5$ & $-43.8 \pm 17.8$ & $-37.6 \pm 14.3$ \\
\hline
\end{tabular}

Table A1 - Converting observed surface elevation trends into mass balance at the OSU clusters (Equation A2). A negligible rate of change in firn density, but appreciable associated uncertainty, is prescribed to approximate the range of contrasting in situ and model firn compaction estimates.

\begin{tabular}{|l|c|c|c|c|c|}
\hline \multicolumn{1}{|c|}{ Site } & $\begin{array}{c}\dot{\boldsymbol{H}}_{\text {ice }} \\
(\mathbf{m} / \mathbf{a})\end{array}$ & $\begin{array}{c}\boldsymbol{\rho}_{\text {ice }} \\
\left(\mathbf{k g} / \mathbf{m}^{3}\right)\end{array}$ & $\begin{array}{c}\dot{\boldsymbol{\rho}}_{\text {firn }} \\
\left(\mathbf{k g} / \mathbf{m}^{\mathbf{3}} / \mathbf{a}\right)\end{array}$ & $\begin{array}{c}\boldsymbol{H}_{\text {firn }} \\
(\mathbf{m})\end{array}$ & $\begin{array}{c}\dot{\boldsymbol{m}} \\
\left(\mathbf{k g} / \mathbf{m}^{\mathbf{3}} / \mathbf{a}\right)\end{array}$ \\
\hline Western & -0.17 & 917 & $0 \pm 5$ & 15 & $-150 \pm 75$ \\
Central & -0.02 & 917 & $0 \pm 5$ & 15 & $-15 \pm 75$ \\
Dye-3 East & -0.06 & 917 & $0 \pm 5$ & 15 & $-55 \pm 75$ \\
Dye-3 Divide & 0.05 & 917 & $0 \pm 5$ & 15 & $46 \pm 75$ \\
\hline
\end{tabular}




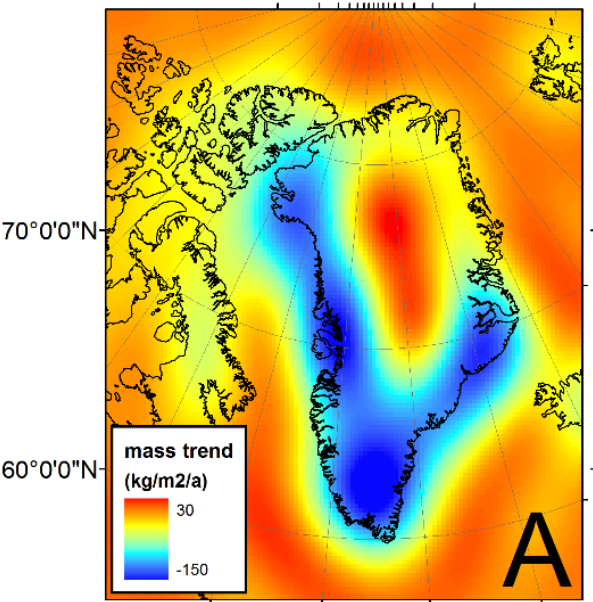

$60^{\circ} 0^{\prime} 0^{\prime \prime W}$



$40^{\circ} 0^{\prime} 0 \mathrm{OW}$



$60^{\circ} 0^{\circ} 0^{\prime \prime} \mathrm{W}$

$40^{\circ} 0^{\circ} \mathrm{O} \mathrm{W}$

Figure 1 - A: Spherical harmonic representation of cryosphere-attributed mass trends derived from gravimetry (Luthcke et al., 2013). B: Fractional ice coverage, derived from glacier

1068

1069

1070

1071

1072

1073

1074

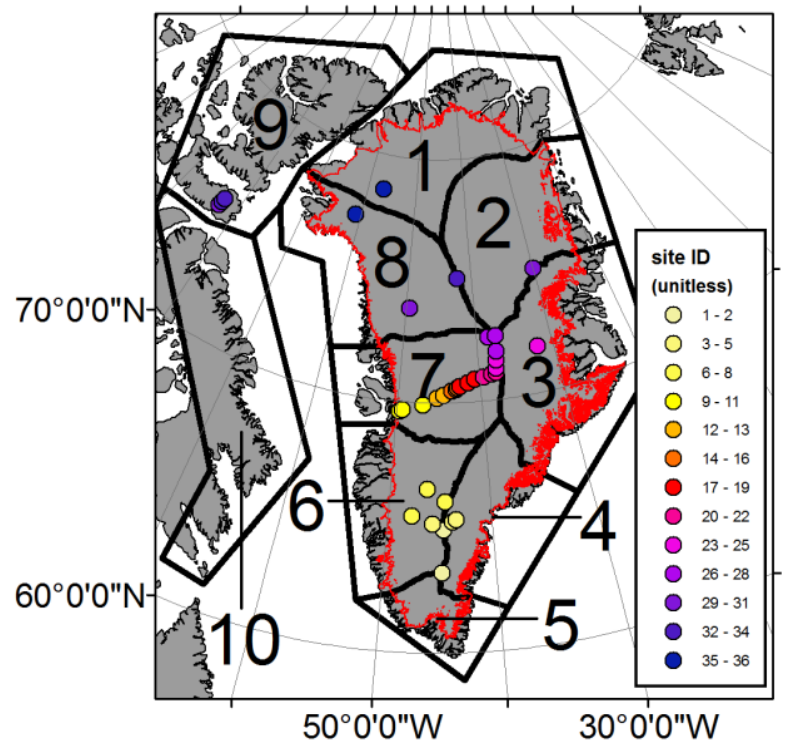

Figure 2 - The ten sectors in which mass balance is assessed. The eight Greenland sectors correspond to the major ice sheet drainage systems delineated by Zwally et al. (2012). Red line denotes the ice sheet margin. Points denote locations of in situ mass balance observations (Table 1). 
1082 1083 1084 1085 1086 1087

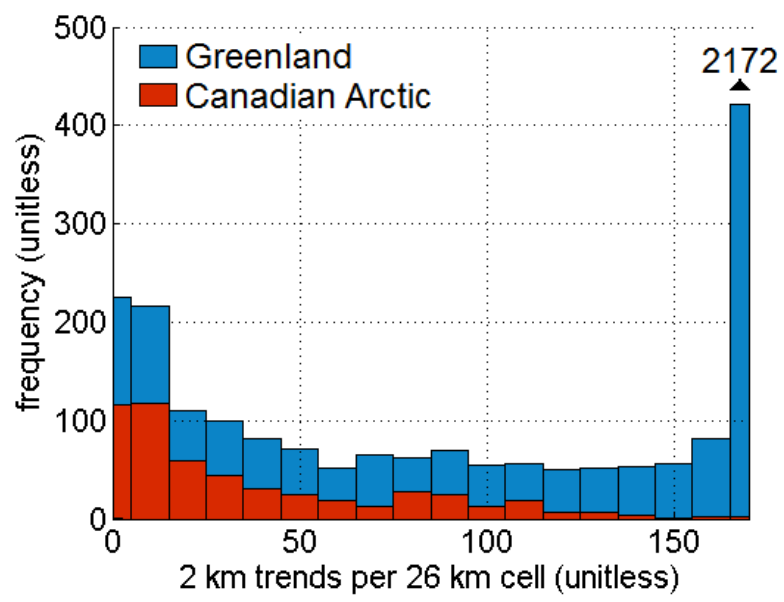

Figure 3 - Stacked histograms of the altimetry-derived $2 \mathrm{~km}$ resolution ice surface elevation trends comprising the mean $26 \mathrm{~km}$ resolution surface elevation trends in both Greenland and the Canadian Arctic.

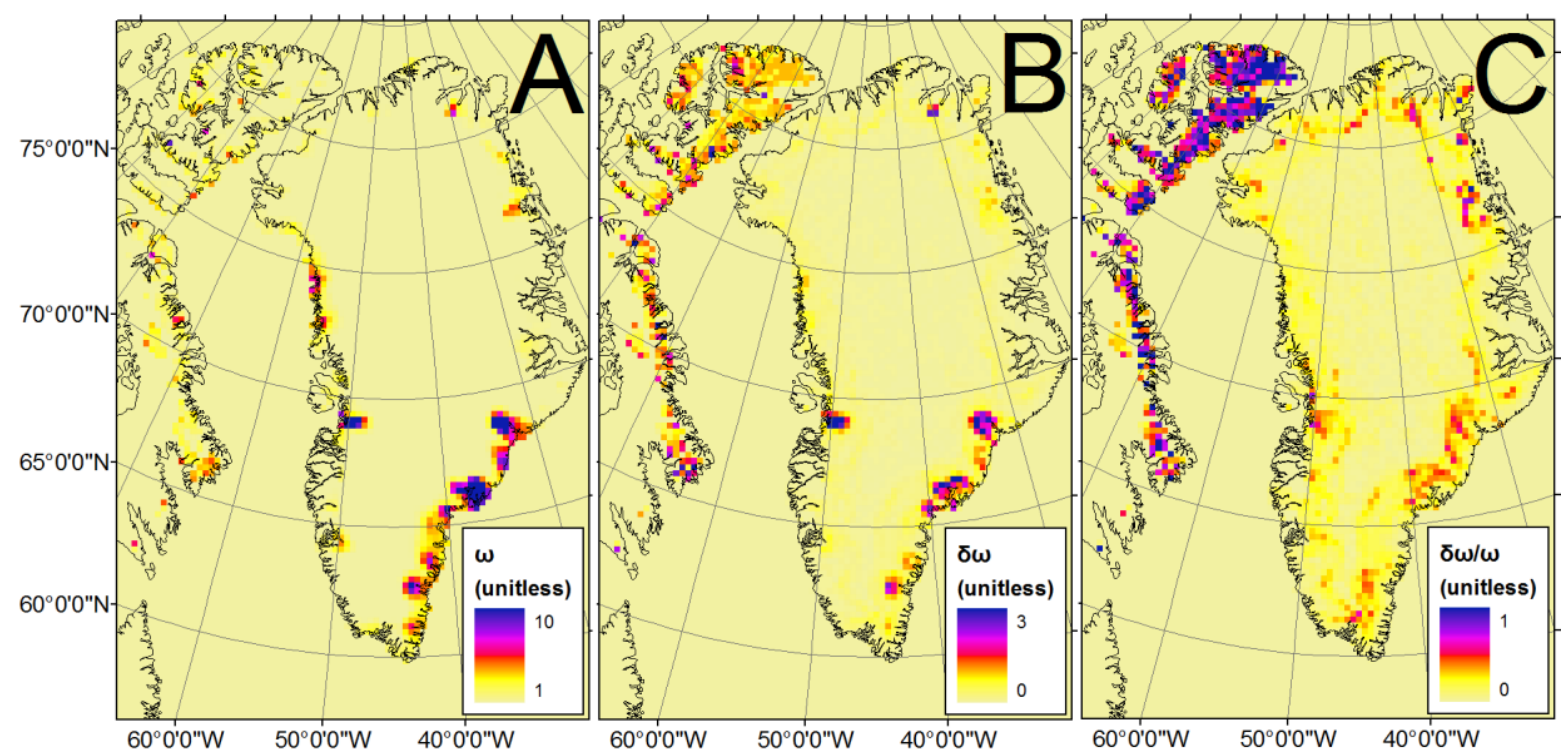

Figure 4 - A: The successive over relaxation-type parameter $(\omega)$ derived from normalizing altimetry-observed surface elevation trends. B: The $1 \sigma$ uncertainty associated with $\omega(\delta \omega)$. C: Relative uncertainty in $\omega$, expressed as $\delta \omega / \omega(\mathrm{B} / \mathrm{A})$. Color scales saturate at maximum values. 

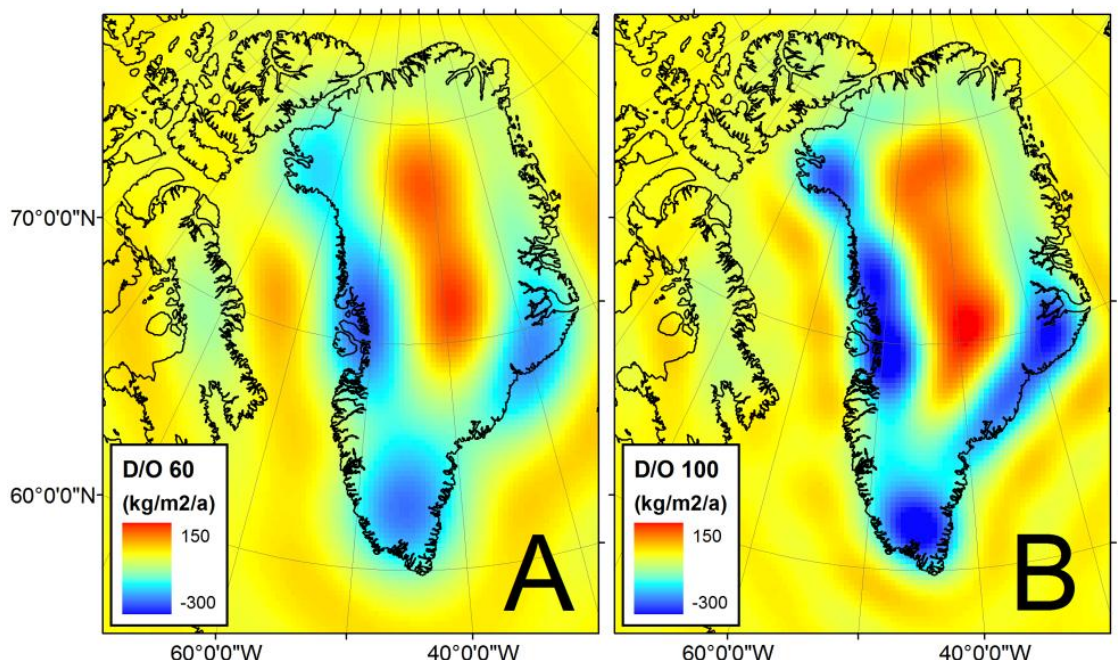

$60^{\circ} 0^{\prime} \mathrm{O}^{\prime \prime} \mathrm{W} \quad 40^{\circ} 0^{\prime} \mathrm{O}^{\mathrm{O}} \mathrm{W}$

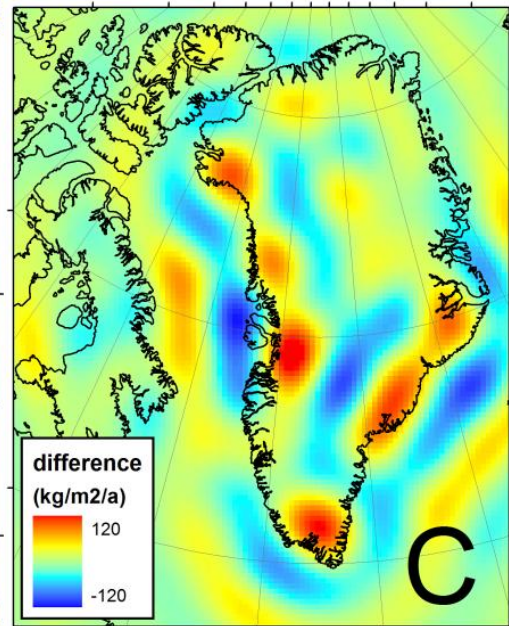

$60^{\circ} 0^{\prime} 0^{\prime \prime} \mathrm{W}$

$40^{\circ} 0^{\prime} \mathrm{O}^{\prime \prime} \mathrm{W}$

Figure 5 - A: HIGA-inferred inferred mass trends $(\dot{m})$ converted to spherical harmonic solutions of degree/order (D/O) 100 and then subsequently truncated to D/O 60. B: Equivalent D/O 100 spherical harmonic solution. C: Differencing the D/O 100 solution from the D/O 60 solution provides an estimate of the potential truncation error associated with using a $200 \mathrm{~km}$ Gaussian inversion filter, which is characteristic of a D/O 100 solution. Color scales saturate at minimum and maximum values.


Figure 6 - Local total uncertainty in HIGA-inferred mass balance $(\mathbf{C} ; \delta \dot{m})$, taken as the quadratic sum of random $\left(\mathbf{A} ; \delta \dot{m}_{r a d}\right)$ and systematic $\left(\mathbf{B} ; \delta \dot{m}_{s y s}\right.$, Figure $\left.5 \mathrm{C}\right)$ uncertainties. Random $2 \sigma$ uncertainty results from stochastic inversion, while systematic uncertainty results from "ringing" or spherical harmonic truncation bias. Note the different color scale of subplot $\mathbf{B}$. Color scales saturate at maximum values. 


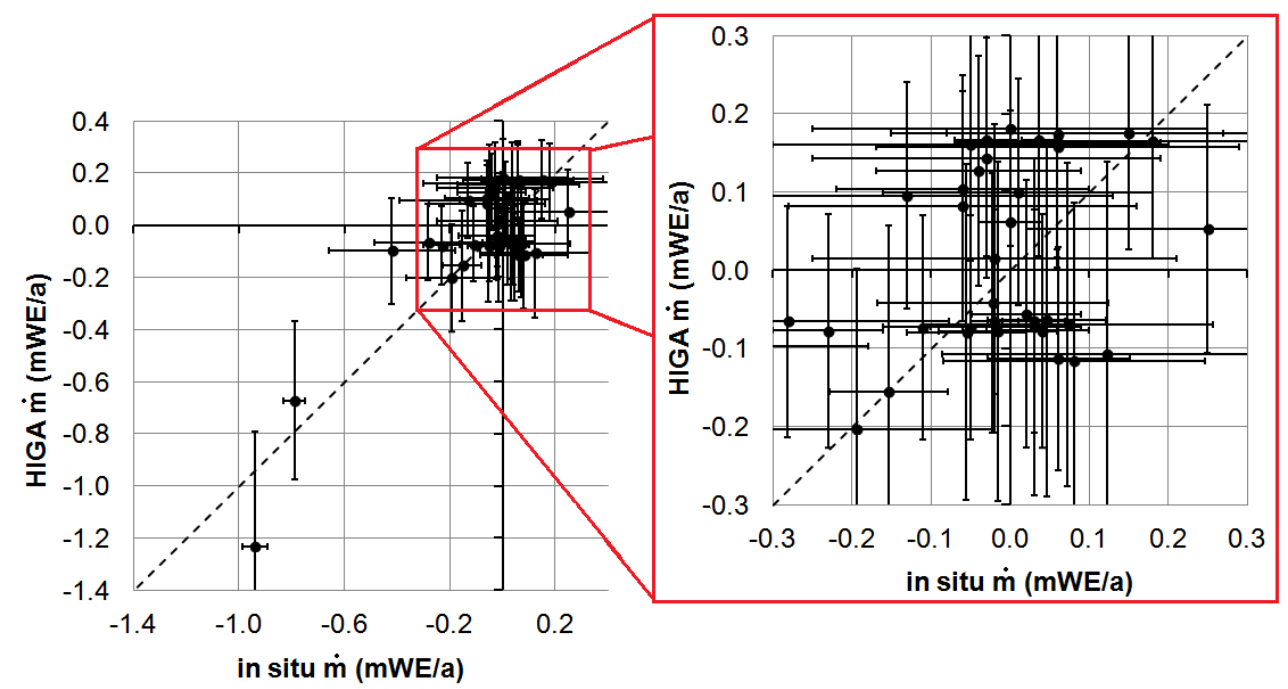

Figure 7 - Comparison of HIGA-inferred mass balance $(\dot{m})$ versus in situ observations in Greenland and the Canadian Arctic (Figure 2 and Table 1). Vertical and horizontal whiskers denote respective uncertainties. Line $y=x$ shown for reference.

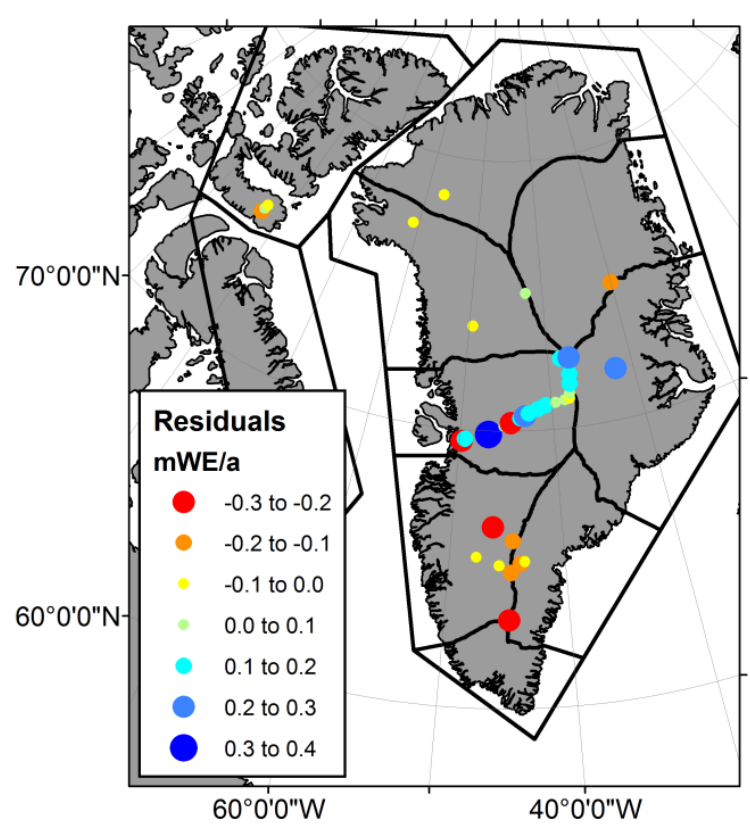

Figure 8 - Residual of HIGA-inferred mass balance minus in situ observed mass balance at forty sites across Greenland and the Canadian Arctic. Warm (cool) colors denote an underestimation (overestimation) of observed mass balance by the inversion product. 


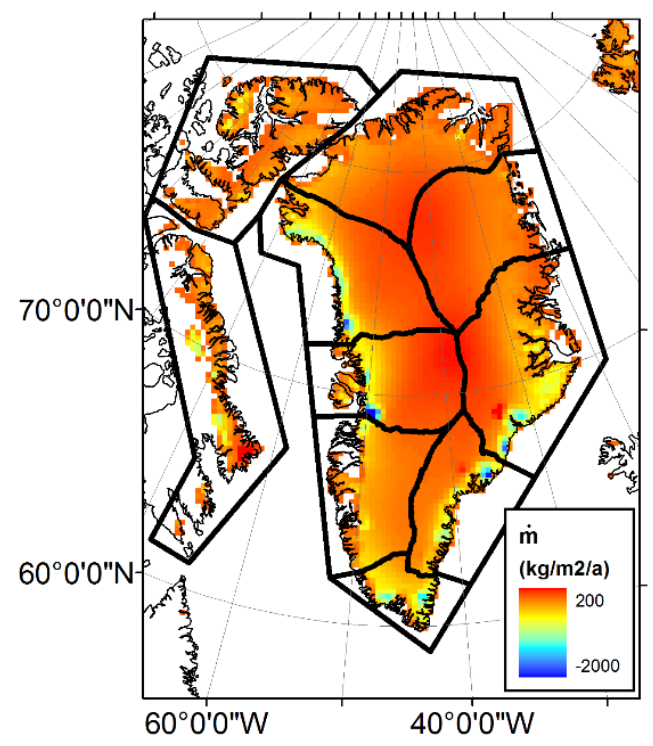

Figure 9 - HIGA-inferred mass balance $(\dot{m})$ in ten geographic sectors across Greenland and the Canadian Arctic during the Sep-2003 to Oct-2009 study period. Associated uncertainty in point scale mass balance shown in Figure 6. Color scales saturate at minimum and maximum values.

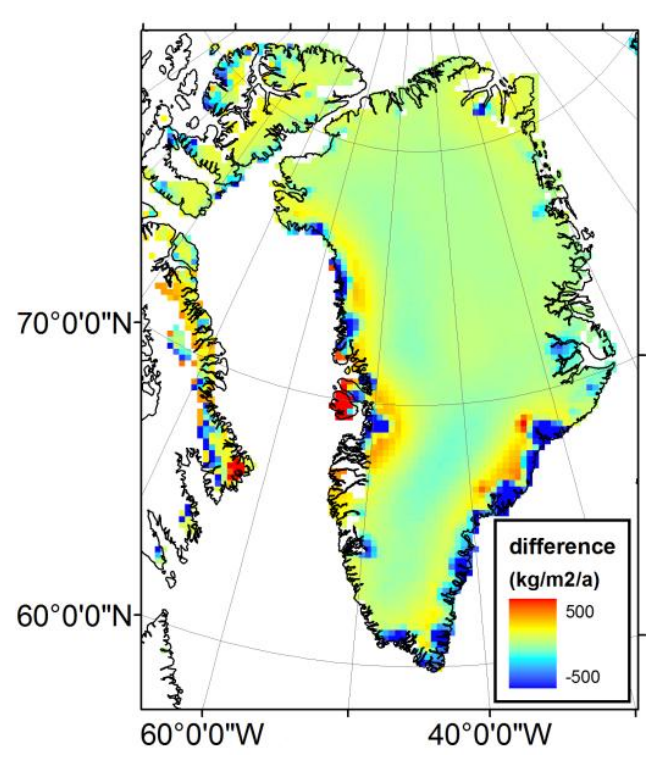

Figure 10 - Difference between HIGA-inferred mass balance and a gravimetry-only inversion (Colgan et al., 2013). Color scale saturates at minimum and maximum values. 

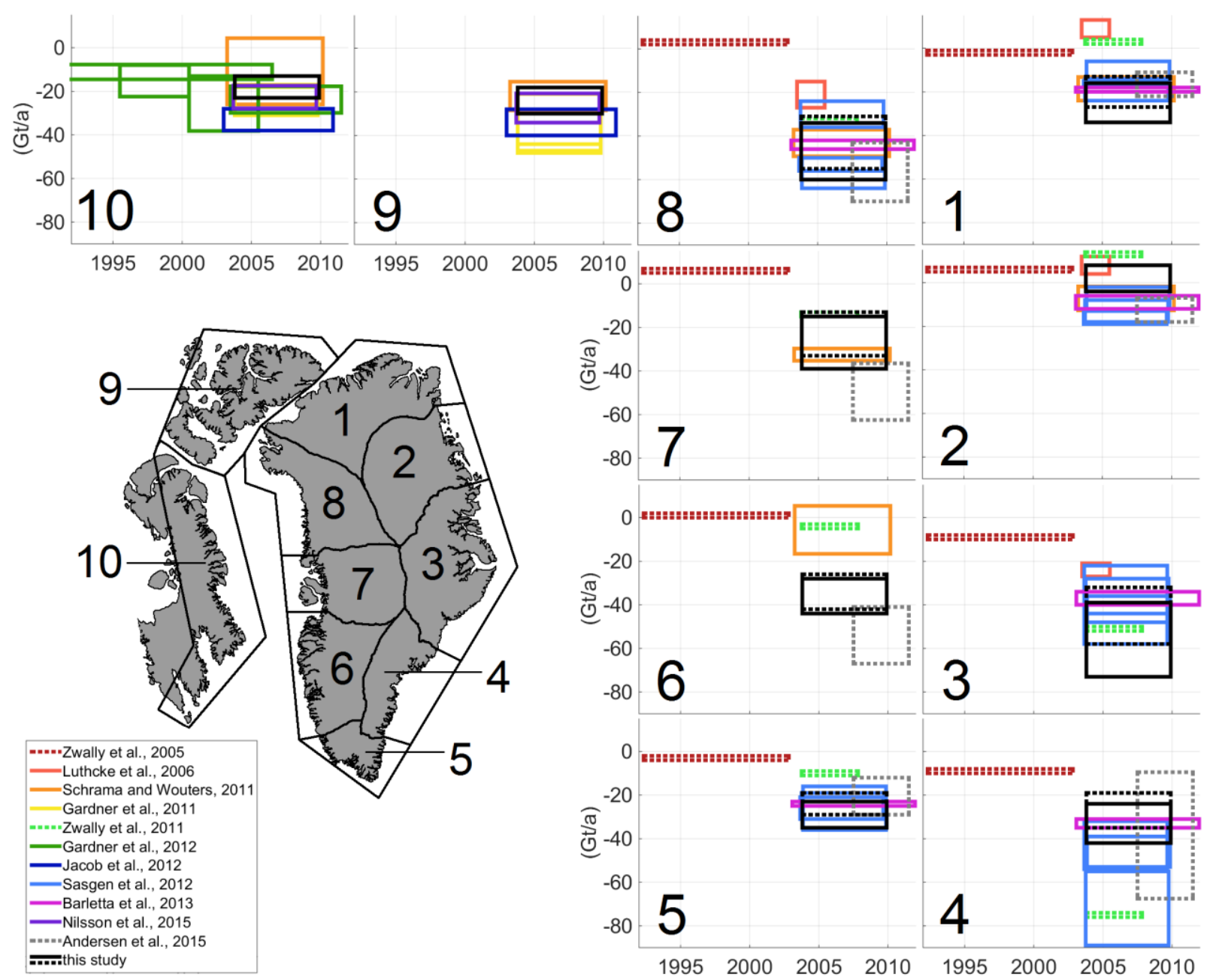

Figure 11 - A comparison of similar sector scale mass balance estimates and associated uncertainties across Greenland and the Canadian Arctic. Dashed lines denote estimates that pertain to the Greenland ice sheet proper (i.e. exclusive of peripheral glaciers). Jacob et al. (2012) estimates pertain to Canada, while Sasgen et al. (2012) estimates pertain to Greenland. 
1142

1143

1144

1145

1146

1147

1148

1149

1150

1151

1152

1153

1154

1155

1156

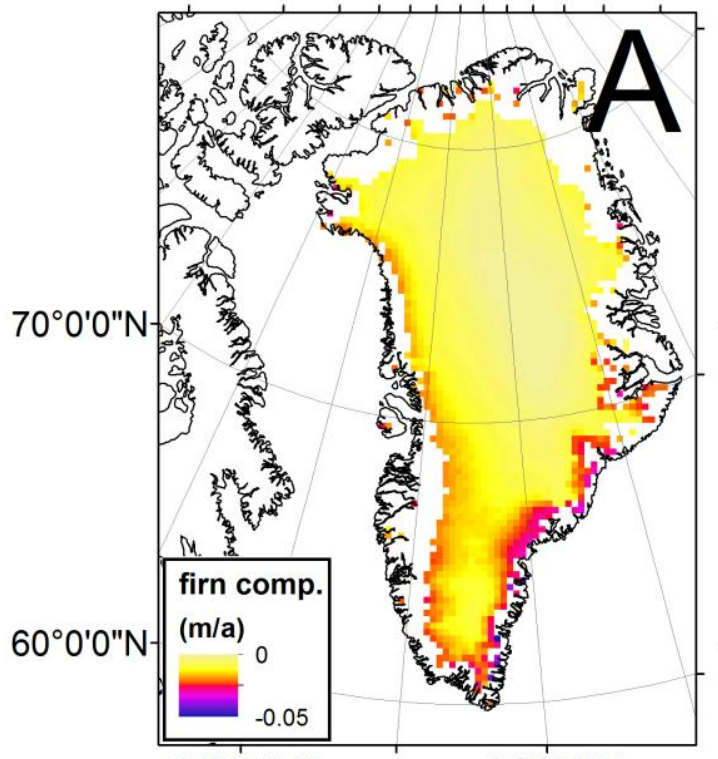

$60^{\circ} 0^{\prime} 0^{\prime \prime} \mathrm{W}$

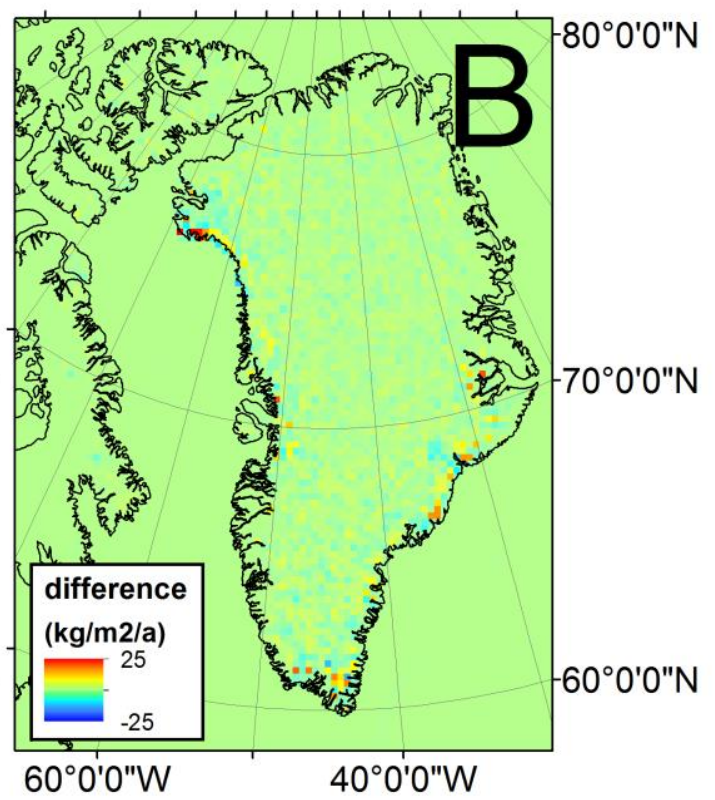

$60^{\circ} 0^{\prime} 0 " \mathrm{~W} \quad 40^{\circ} 0^{\prime} 0 " \mathrm{~W}$

Figure 12 - A: Correction for firn compaction (or firn air content) trend over the Sep-2003 to Oct-2009 (Sørensen et al., 2011). B: Difference in inferred mass balance between the HIGA product presented here (Figure 9) and the firn compaction corrected sensitivity analysis.
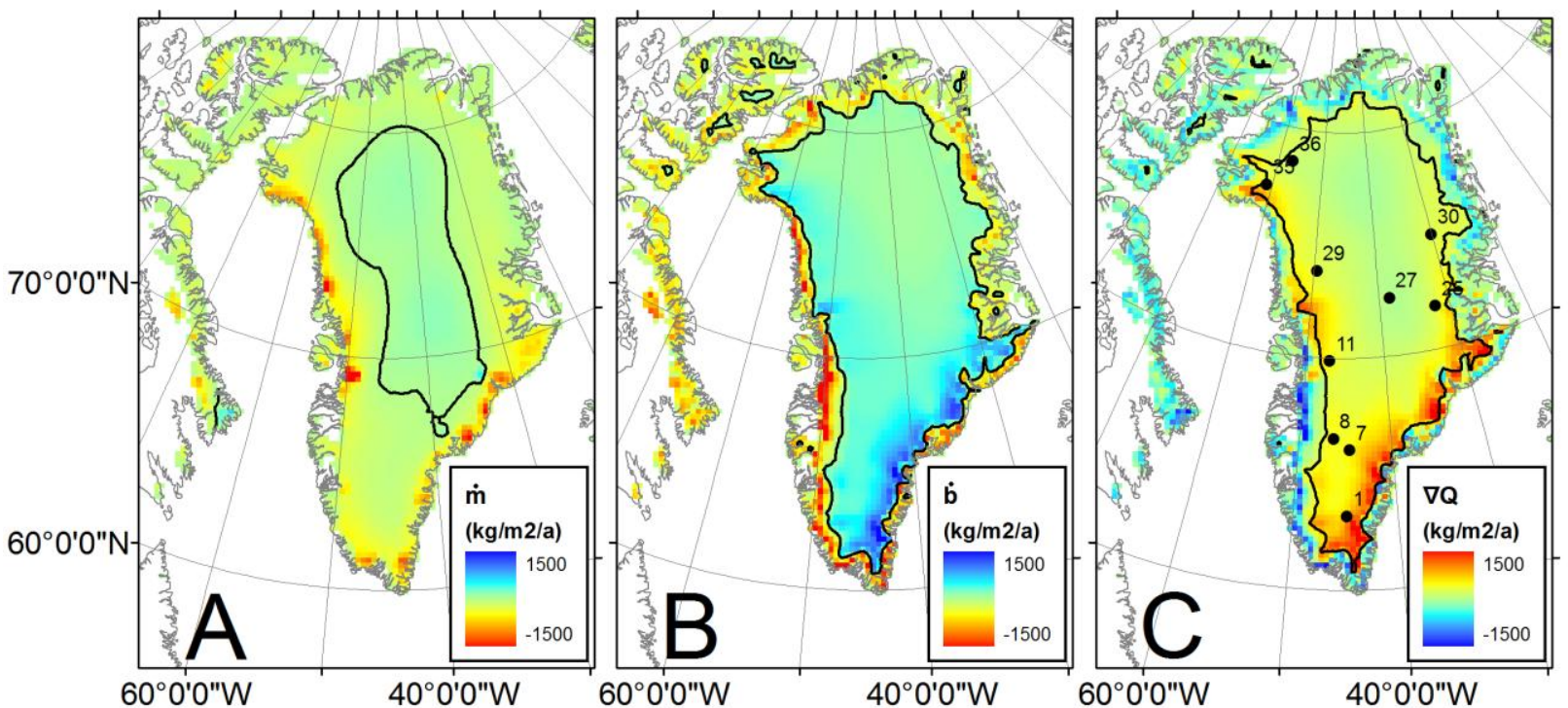

Figure 13- Terms in the transient glacier continuity equation (Eq. 5) during the Sep-2003 to Oct2009 study period. A: HIGA-inferred mass balance $(\dot{m})$. B: MAR modelled surface mass balance $(\dot{b})$. C: Residual divergence of ice flux $(\nabla Q)$. The $\nabla Q$ color scale is reversed to maintain blue shading for mass gain and red shading for mass loss in all subplots. Color scales saturate at minimum and maximum values. Black contours denote $0 \mathrm{~kg} / \mathrm{m}^{2} / \mathrm{a}$. Black dots depict some in situ observations, labelled with site ID (Table 1). 


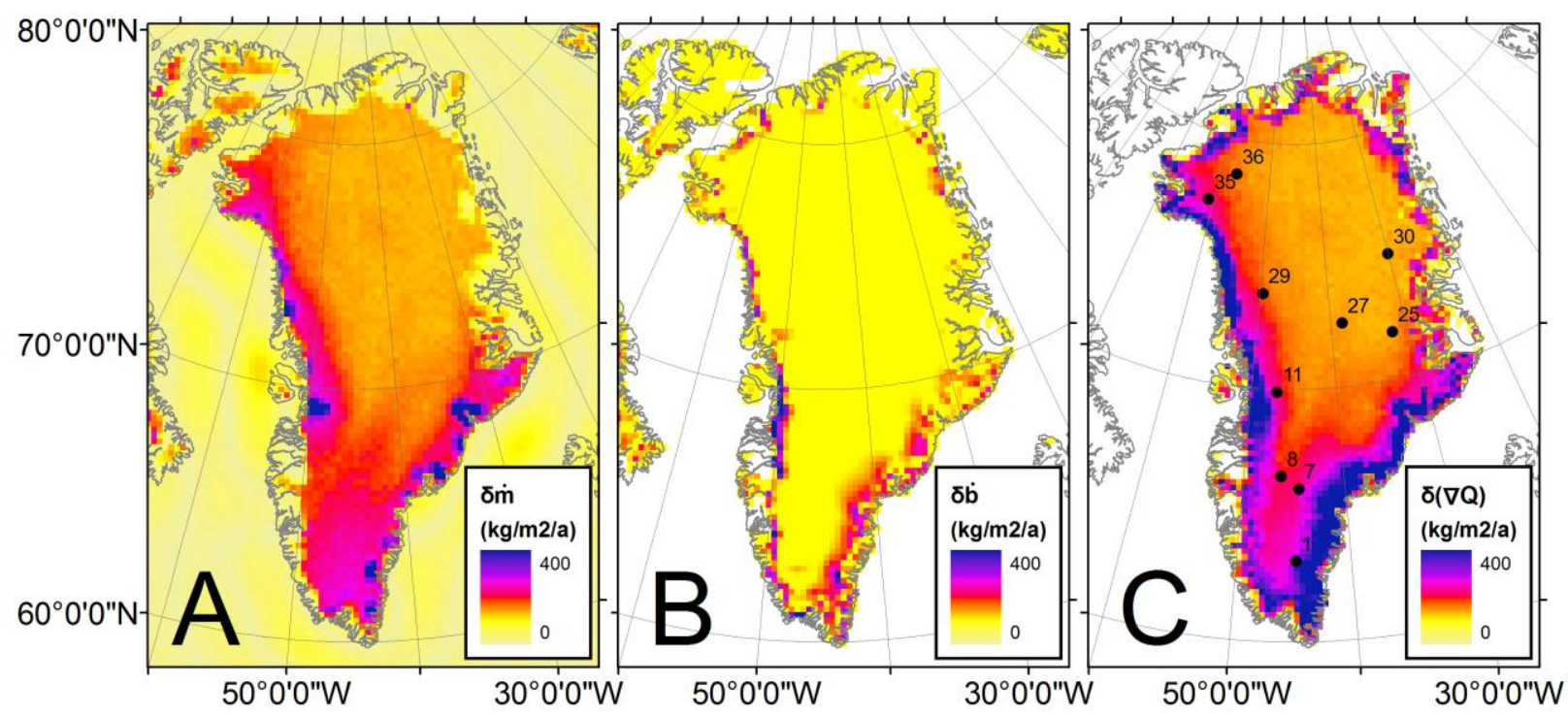

Figure 14 - Uncertainty associated with terms in the transient glacier continuity equation (Eq. 5) during the Sep-2003 to Oct-2009 study period (Figure 6C). A: Uncertainty in HIGA-inferred mass balance $(\delta \dot{m})$. B: Uncertainty in MAR modelled surface mass balance $(\delta \dot{b})$. C: Uncertainty in residual divergence of ice flux $(\delta(\nabla Q))$. Black dots depict some in situ observations, labelled with site ID (Table 1). Color scales saturate at maximum values.



Figure 15 - HIGA-inferred mass balance $(\dot{m})$ versus MAR modelled surface mass balance $(\dot{b})$ in the Canadian Arctic (Sectors 9 and 10) over the Sep-2003 to Oct-2009 study period. Vertical and horizontal whiskers denote associated uncertainties. Solid line denotes linear best fit. Dashed line denotes $y=x$ for reference. 